Colloids Surfaces A, 521, 92-104 (2017), https://doi.org/10.1016/j.colsurfa.2016.06.018

\title{
Production and characterization of stable foams with fine bubbles from solutions of hydrophobin HFBII and its mixtures with other proteins ${ }^{\text {hy }}$
}

\author{
Lydia M. Dimitrova ${ }^{a}$, Plamen V. Petkov ${ }^{a}$, Peter A. Kralchevsky ${ }^{a}$, Simeon D. Stoyanov ${ }^{\text {b,c,d,*, }}$ \\ Eddie G. Pelan ${ }^{\mathrm{b}}$ \\ a Department of Chemical and Pharmaceutical Engineering, Faculty of Chemistry and Pharmacy, \\ Sofia University, 1164 Sofia, Bulgaria \\ ${ }^{\mathrm{b}}$ Unilever Research \& Development Vlaardingen, 3133AT Vlaardingen, The Netherlands \\ ${ }^{c}$ Laboratory of Physical Chemistry and Colloid Science, Wageningen University, 6703 HB Wageningen, \\ The Netherlands \\ ${ }^{\mathrm{d}}$ Department of Mechanical Engineering, University College London, WC1E 7JE, UK
}

\begin{abstract}
Hydrophobins are proteins that are excellent foam stabilizers. We investigated the effects of $\mathrm{pH}$ and addition of other proteins on the foaminess, bubble size, and stability of foams from aqueous solutions of the protein HFBII hydrophobin. The produced stable foams have bubbles of radii smaller than $40 \mu \mathrm{m}$ that obey the lognormal distribution. The overrun of most foams is in the range from 5 to 8 , which indicates a good foaminess. The foam longevity is characterized by the time dependences of the foam volume and weight. A combined quantitative criterion for stability, the degree of foam conservation, is proposed. The produced foams are stable for at least 12-17 days. The high foam stability can be explained with the formation of dense hydrophobin adsorption layers, which are impermeable to gas transfer and block the Ostwald ripening (foam disproportionation). In addition, the population of small bubbles formed in the HFBII solutions blocks the drainage of water through the Plateau borders in the foam. The variation of $\mathrm{pH}$ does not essentially affect the foaminess and foam stability. The addition of "regular" proteins, such as beta-lactoglobulin, ovalbumin and bovine serum albumin, to the HFBII solutions does not deteriorate the quality and stability of the produced foams up to $94 \%$ weight fraction of the added protein. The results and conclusions from the present study could be useful for the applications of hydrophobins as foam stabilizers.
\end{abstract}

Keywords: HFBII hydrophobin; Foaminess; Foam stability; Foam drainage; Ostwald ripening; Bubble size distribution

is This article is dedicated to Prof. Dr. Victor M. Starov on the occasion of his $70^{\text {th }}$ birthday.

* Corresponding author. E-mail address: Simeon.Stoyanov@unilever.com (S.D. Stoyanov). 


\section{Introduction}

One route towards increasing the stability of liquid foams is the addition of polymers, particles and proteins [1-7]. The hydrophobins are the best foam stabilizers among the proteins [8-10]. Most proteins are poor foaming agents - they cannot prevent the action of the main destabilizing factors: Ostwald ripening (coarsening), bubble coalescence (film rupture), and foam drainage [2,11-13]. The hydrophobins cover the bubbles with a highly elastic adsorption layer, which suppresses both foam disproportionation and bubble coalescence, without increasing the viscosity of the aqueous phase [8-10,14]. The hydrophobins are also used to stabilize oil-in-water emulsions $[15,16]$ and aerated emulsions $[17,18]$. The adhesive properties of hydrophobins have been utilized for immobilizing functional molecules at surfaces [19], and for surface modification by appropriate coatings [20].

Hydrophobins are proteins exclusively produced by filamentous fungi, including some mushrooms [21-23]. They are stable and relatively small protein molecules. For example, hydrophobin HFBII, which is used in the present study, consists of 70 amino acids. Its molecule is rich in cysteine and is interconnected with four disulfide bonds. The structure of HFBII determined from crystallized samples [24] shows that it is a single-domain protein with dimensions of $24 \times 27 \times 30 \AA$. On the surface of HFBII molecule, a hydrophobic patch and a larger hydrophilic portion are exposed, which give the molecule the character of an amphiphile (Janus-like particle); for details see [21-25]. The hydrophobins are very hard to denature - their aqueous solutions have been heated to $90{ }^{\circ} \mathrm{C}$ without any sign of protein denaturing [21,25]. There are no evidences for denaturing of hydrophobins by surfactants or upon adsorption at interfaces. In this respect, the hydrophobin molecules behave like particles, in contrast with the disordered proteins (like $\beta$-casein), which behave as polymers [2].

At an air/water or oil/water interface, the adsorption layer of HFBII fast solidifies, i.e. it acquires surface shear elasticity, which is higher than that measured for all other investigated proteins [10,26-30]. The hydrophobin adsorption layers possess also a high dilatational elasticity and the hydrophobin adsorption at the air/water interface is irreversible [31-36]. As a rule, surfactants are able to displace adsorbed proteins from the air/water interface [37]. However, it has been observed that having once adsorbed at the solution surface, HFBII cannot be displaced by sodium dodecyl sulfate (SDS), even at concentrations above the CMC [35]. 
The hydrophobin molecules are "sticky" - they adhere to each other $[8,38]$, as well as to other macromolecules and solid walls [30,39]. These adhesive interactions lead to irreversible aggregation of the HFBII molecules in the bulk of solution. Initially, the tetramers are the most abundant oligomers in the $\mathrm{mg} / \mathrm{mL}$ concentration range [40-43]. The mean aggregate size increases with time, which was studied by light scattering [8]. Micrometer-sized and larger aggregates are directly visible by optical microscopy. They can be destroyed by sonication of the solution. However, after that the aggregate growth commences again [8]. Atomic force microscopy (AFM), which has been used for determining surface interactions of relevance to food foams [44], has been applied also to investigate the adhesion of HFBII aggregates to hydrophobin adsorption layers at the air/water interface [33].

The studies on foam films stabilized with HFBII showed the formation of both thicker films, stabilized by sandwiched aggregates, and of 6-nm thick self-assembled hydrophobin bilayers (S-bilayers) due to the strong cohesion of the HFBII monolayers on the two film surfaces $[28,45,46]$. It is remarkable, that strong cohesion is present not only between the hydrophobic parts of the HFBII molecules, but also between their hydrophilic moieties [30,33,46]. Whatever the nature of the cohesive forces between the HFBII molecules might be, they lead to the formation of a tightly interlocking monolayer of Janus-like particles at the air water interface [47]. Such dense adsorption layers can suppress the Ostwald ripening and the coalescence of bubbles or drops [48]. In the case of submillimeter bubbles and films of low permeability to gas transfer (as in shaving foams and protein stabilized foams), the bubbles have curved surfaces and the Ostwald ripening is one of the main reasons for foam coarsening [48]. Here, the terms "Ostwald ripening” and "foam disproportionation" are used as synonyms [49].

Our goal in the present article is to investigate the effects of $\mathrm{pH}$ and protein additives on the foaminess of HFBII aqueous solutions, as well as on the bubble size and foam stability. The protein additives are globular proteins: $\beta$-lactoglobulin, ovalbumin and bovine serum albumin. The foam volume and weight are measured as functions of time. The mean bubble radius, $R_{32}$, is determined by image analysis of photographs of the foams and the mean radius of the protein aggregates, $a_{32}$, is estimated from the foam overrun. Section 2 describes the used materials and methods for foam production and characterization. Sections 3 and 4 present the results on the effects of $\mathrm{pH}$ and protein additives, respectively. In particular, we have investigated whether it is possible to replace a part of hydrophobin (at present, an expensive protein with a view to 
industrial applications) with another protein without deteriorating the foaminess and foam longevity.

\section{Materials and methods}

\subsection{Materials}

The proteins used in our experiments were as follows:

(1) Hydrophobin HFBII; 70 amino acids; molecular weight $M_{\mathrm{w}}=7.2 \mathrm{kDa} ; 4$ disulfide bonds. The used HFBII sample, provided as a gift by Unilever R\&D, was produced via fermentation using Trichoderma reesei [45].

(2) $\beta$-lactoglobulin (BLG) from bovine milk; 162 amino acids; $M_{\mathrm{w}}=18.3 \mathrm{kDa} ; 2$ disulfide bonds. The used sample was product of Sigma ( $\geq 90 \%$, Cat. No. L0130).

(3) Ovalbumin (OVA) from chicken egg white; 385 amino acids; $M_{\mathrm{w}}=45 \mathrm{kDa}$; 1 disulfide bond. The used sample was product of Sigma ( $\geq 98 \%$, Cat. No. A5503).

(4) Bovine serum albumin (BSA); 580 amino acids; $66.4 \mathrm{kDa} ; 17$ disulfide bonds. The used sample was product of Sigma ( $\geq 97 \%$, Cat. No. A7511).

\subsection{Experimental methods}

In our experiments, $3 \mathrm{~mL}$ protein solutions were placed in $25 \mathrm{~mL}$ beakers. Next, the protein solutions were sonicated for $20 \mathrm{~s}$ by placing the beakers in a water bath. Thus, the protein aggregates (at least the larger ones) were dispersed. Furthermore, foam was produced by using two mixers: Nescafe frappe NE-12E (mixer 1) operating at a rotation speed of 16-20 krpm and Mulifunction Frothier 464701 (mixer 2) operating at a rotation speed of 6-8 krpm. At the lower protein concentrations, ( $\leq 0.5 \mathrm{wt} \% \mathrm{HFBII})$, the use of mixer 1 for $60 \mathrm{~s}$ was insufficient to produce fine foam. In this case, the foam was generated by consecutive use of mixers 1 and 2 , for $60 \mathrm{~s}$ each.

Immediately after the foam production, a part of it was placed in a Petri dish (of depth $\approx 1.0 \mathrm{~mm}$ ) and covered with a plate of optical glass to prevent the evaporation of water. Photographs (video frames) of the foam were taken by microscope. They were processed by semi-automatic image analysis to obtain the bubble size distribution in the foam. The bubble diameter (in the range between 2 and $150 \mu \mathrm{m}$ ) was determined manually by placing a circle with 
adjustable diameter on the periphery of each bubble visible on the photograph. The radius of the circle is automatically recorded by means of a computer. In the case of ellipsoidal bubbles, a circle of radius intermediate between the semi-major and semi-minor axes of the ellipse was placed. The images were processed using image analysis software. For the foam from a given solution, the bubble-size distribution is constructed on the basis of data for the measured diameters of 250 - 1400 bubbles (all bubbles visible on several photographs of the same foam). The lower limit (250 bubbles) is for the foams with larger bubbles.

\subsection{Methods for foam characterization}

The foams with hydrophobin are usually viscous and a layer of foam (cling) remains deposited on the walls of the glass beaker. For this reason, we placed the foams in $20 \mathrm{~mL}$ polypropylene syringes. To do that, the plunger was initially removed. After placing the foam, we carefully returned back the plunger to its position and gently pressed the foam until it was compacted. Sometimes, cavities remained inside the foam. We usually removed them by taking off the gas through a small capillary, inserted from the side of the nozzle of the syringe. Next, the nozzle was plugged. In the experiments described in this section, no $\mathrm{NaN}_{3}$ was added to the protein solutions for antibacterial protection. Instead, the syringes with the foams were stored in a refrigerator at $4{ }^{\circ} \mathrm{C}$. (If the foams are stored at $25{ }^{\circ} \mathrm{C}$, their longevity markedly decreases.) Our experiments showed that the material of the container (polypropylene or glass) does not affect the foam stability. A possible reason could be that solid surfaces in contact with hydrophobin solutions are always covered with adsorption layers of this protein, so that the foam is not in direct contact with the solid substrate.

The placing of the foams in syringes was convenient for the measurements of their volume

and weight, $V_{\mathrm{F}}(t)$ and $G_{\mathrm{F}}(t)$, as functions of time, $t$. Note that $G_{\mathrm{F}}$ is determined by the weight of the liquid contained in the foam without the separated serum (drained liquid). In the presence of HFBII, initially (at $t=0$ ), all the water ( $3 \mathrm{~mL}$ ) was incorporated in the foam. With time, some water (serum) might be released below the foam. This serum was removed through the nozzle of the syringe, and then the foam weight, $G_{\mathrm{F}}(t)$, was measured for the respective moment of time, $t$.

Having determined the foam volume and weight, $V_{\mathrm{F}}(t)$ and $G_{\mathrm{F}}(t)$, we calculated the volume fraction of gas in the foam, $\Phi$, from the formula: 


$$
\Phi(t)=\frac{V_{\mathrm{F}}(t)-G_{\mathrm{F}}(t) / \rho_{\mathrm{W}}}{V_{\mathrm{F}}(t)}
$$

Here, $\rho_{\mathrm{w}} \approx 1 \mathrm{~g} / \mathrm{cm}^{3}$ is the mass density of the water phase.

Furthermore, the overrun was estimated from the formula [50]:

$$
O_{\mathrm{vr}}(t)=\frac{\text { Foam volume }- \text { Solution volume }}{\text { Solution volume }}=\frac{\Phi(t)}{1-\Phi(t)}
$$

The greater the overrun, the greater the amount of foam produced from the solution of a given foaming agent. In this study, the overrun is presented in its absolute value (rather than in \%), because of its relatively large values. The initial overrun was estimated assuming that there is no drainage of liquid out of the foam at $t=0$, as observed in our experiments.

By using image analysis, a set of data $\left\{R_{i}\right\}_{i=1}^{N}$ has been obtained for each foam, where $R_{i}$ is the radius of the $i$-th bubble in the set and $N$ is the total number of bubbles. For every foam sample, the arithmetic mean bubble radius, $R_{10}$, and the volume-to-surface mean bubble radius, $R_{32}$, have been calculated using the following standard formulas:

$$
R_{10}=\frac{\sum_{i=1}^{N} R_{i}}{N}, \quad R_{32}=\frac{\sum_{i=1}^{N} R_{i}^{3}}{\sum_{i=1}^{N} R_{i}^{2}}
$$

where the summation is carried out over all bubbles in the foam. Extending the mass-balance approach used to characterize particle and protein stabilized emulsions [51-54], one can derive a formula (see Appendix A), which relates the foam overrun with $R_{32}$ and $a_{32}$ [55]:

$$
O_{\mathrm{vr}}=\frac{w_{\mathrm{p}} \rho_{\mathrm{w}}}{4 \varphi_{\mathrm{a}} \rho_{\mathrm{p}}} \frac{R_{32}}{a_{32}}
$$

To obtain Eq. (4), it is assumed that the protein is present in the form of particles (protein molecules and aggregates) of mean volume-to-surface radius $a_{32} ; w_{\mathrm{p}}$ is the weight fraction of protein in the solution; $\rho_{\mathrm{p}}$ is the protein mass density; it is assumed that during the foaming, all particles have been adsorbed on the surfaces of the formed bubbles; $\varphi_{\mathrm{a}}$ is the area fraction covered by particles at the air/water interface (at the bubble surface). For a close packing of 
monodisperse spherical particles, $\varphi_{\mathrm{a}}=\pi / \sqrt{12} \approx 0.907$. For a dense adsorption layer, we could have $\varphi_{\mathrm{a}} \approx 1$. In Eq. (4), if the protein weight fraction, $w_{\mathrm{p}}$ is substituted as absolute value, then $O_{\mathrm{vr}}$ is also obtained as absolute value. (If $w_{\mathrm{p}}$ is substituted as weight percent, then $O_{\mathrm{vr}}$ will be obtained as volume percent.) In our analysis of the produced foams, we estimated $O_{\mathrm{vr}}$ from Eq. (2), and the result, together with $R_{32}$, was substituted in Eq. (4) to estimate $a_{32}$.

As already mentioned, HFBII is a very "sticky" protein - cohesive forces are acting between both the hydrophobic and hydrophilic portions of its molecules, so that it exists in the form of aggregates in aqueous solutions $[8,38,46]$. For this reason, we believe that the assumption for complete retention of hydrophobin in the foam (negligible fraction of HFBII in the drained water phase) used to derive Eq. (4) is very close to the reality.

\subsection{Evaluation of the bubble size distribution}

The radii of sets of $N$ bubbles were measured by image analysis as explained above. For each set, the radii were ordered in an ascending series, $R_{1}, R_{2}, \ldots, R_{K}$, where $K$ is the total number of different bubble diameters. Each bubble radius, $R_{i}$, appears $n_{i}$ times in the original data set, $i=1,2, \ldots, K$. (For example, if we have measured the diameters of 400 bubbles, it might happen that five different bubbles have radius $R_{i}=10.7 \mu \mathrm{m}$; then, $n_{i}=5$.) The total number of bubbles is:

$$
N=\sum_{i=1}^{K} n_{i}
$$

By definition, the cumulative function $f\left(R_{i}\right)$ is equal to the number of bubbles of radius $R \leq R_{i}$. The function $f\left(R_{i}\right)$ is normalized by the total number of bubbles, $N[56,57]$

$$
f\left(R_{i}\right)=\frac{1}{N} \sum_{j=1}^{i} n_{j}
$$

Using Eq. (6), one can calculate $f\left(R_{i}\right)$ for each experimentally measured bubble radius, $R_{i}$. It turns out that the experimental data obey the lognormal distribution. Its probability density is [56,57]:

$$
p(R)=\frac{1}{\sqrt{2 \pi}} \frac{1}{\ln \sigma} \exp \left[-\frac{\ln ^{2}(R / \bar{R})}{2 \ln ^{2} \sigma}\right] \quad(R>0)
$$


Physically, $p(R) \mathrm{d}(\ln R)$ is the number of bubbles with radius that belongs to the interval $[\ln R, \ln R+\mathrm{d}(\ln R)] ; \bar{R}$ is the mean radius, and $\sigma$ is dimensionless dispersion $(\sigma>1)$. The peak of $p(R)$ defined by Eq. (7) is non-symmetric. The radii of $50 \%$ of the bubbles belong to the interval $\bar{R} / \sigma \leq R \leq \bar{R} \sigma$, which characterizes the bubble polydispersity in the foam. In the limiting case $\sigma \rightarrow 1$, Eq. (7) reduces to the normal (Gaussian) distribution.

The cumulative function, $f(R)$, which corresponds to the lognormal distribution, Eq. (7), is

$$
f(R) \equiv \int_{-\infty}^{\ln R} p(\hat{R}) \mathrm{d}(\ln \hat{R})=\frac{1}{2}\left\{1+\operatorname{erf}\left[\frac{\ln (R / \bar{R})}{\sqrt{2} \ln \sigma}\right]\right\}
$$

where $\hat{R}$ is an integration variable and $\operatorname{erf}(x)$ is the error function [58]. The experimental function $f\left(R_{i}\right)$ given by Eq. (6) was fitted with the theoretical dependence $f(R)$ given by Eq. (8) and $\bar{R}$ and $\sigma$ were determined as adjustable parameters. Next, with the obtained values of $\bar{R}$ and $\sigma$ the theoretical bubble size distribution, $p(R)$, was calculated from Eq. (7).

\section{Results for foams stabilized by HFBII alone}

\subsection{Bubble size distribution}

Here, we present experimental results for the effect of HFBII concentration and $\mathrm{pH}$ on the foaminess and stability of the produced foams. $\mathrm{pH}=6.0$ was the natural $\mathrm{pH}$ of the investigated HFBII solutions. Data have been obtained also at $\mathrm{pH}=4.3$ and 10.1. The variation of $\mathrm{pH}$ is expected to affect the charge of the protein molecules, which could influence the foam stability.

Fig. 1 illustrates the effect of protein concentration on the produced foams. At the higher protein concentration, $0.8 \mathrm{wt} \%$ HFBII (Fig. 1a,b), fine foam was produced by using only mixer 1 for $60 \mathrm{~s}$. As already mentioned, at the lower protein concentration, $0.5 \mathrm{wt} \%$ HFBII (Fig. 1c,d), the use of mixer 1 for $60 \mathrm{~s}$ was insufficient to produce fine foam. In this case, the foam was generated by consecutive use of mixers 1 and 2, for 60 s each. As seen in Fig. 1c,d, both smaller and bigger bubbles have been formed. The bigger bubbles have been mostly produced by the mixer 1, whereas the smaller bubbles have been formed during agitation with the mixer 2 . In general, at the higher protein concentration smaller bubbles have been produced (compare Figs 1a,b with Figs 1c,d), which is to be expected.

Some of the bubbles have ellipsoidal shape, which is better visible in Fig. 1d. The ellipsoidal shape is due to the fast solidification of the HFBII adsorption layers, which preserves 
the instantaneous bubble shape during the stirring [45]. The solidification of the surface of hydrophobin solutions has been detected by the pendant drop method [31]; by capillary meniscus dynamometry [30,36], and by measurements of surface shear elasticity [26-28].
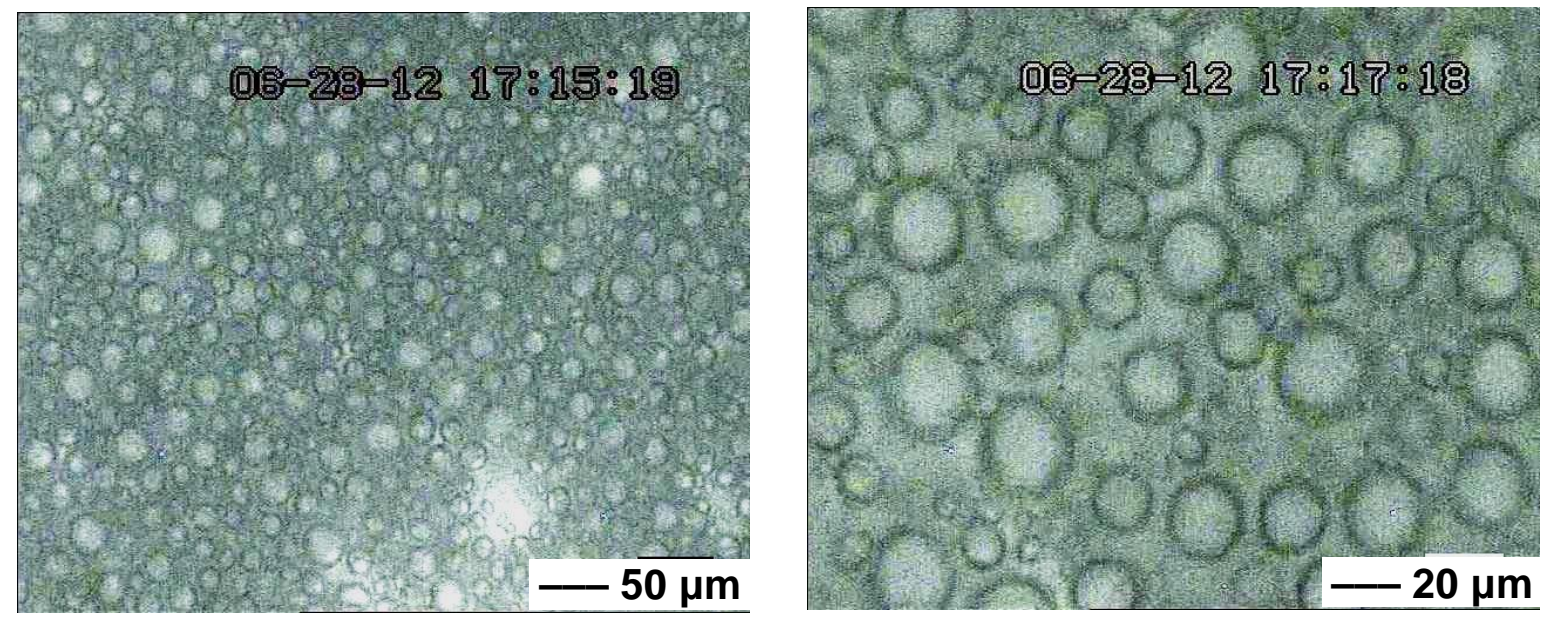

(a)

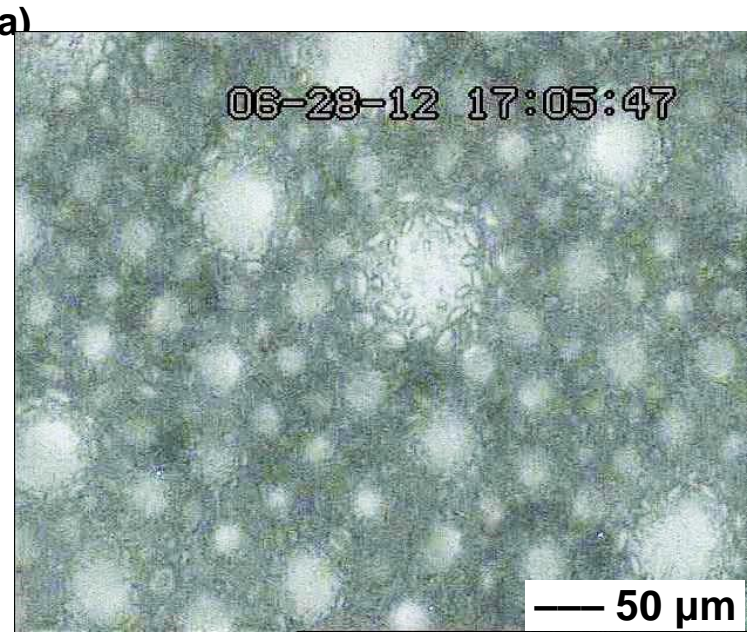

(b)

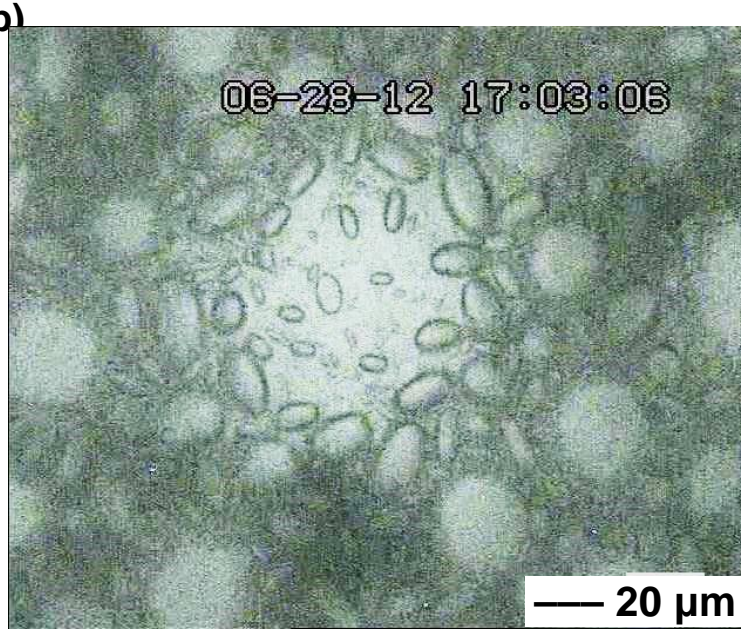

(c)

(d)

Fig. 1. Effect of protein concentration on the produced foams: illustrative photographs of foams from HFBII solutions at $\mathrm{pH}=4.3$ : (a,b) $0.8 \mathrm{wt} \%$ HFBII, mixer 1; (c,d) $0.5 \mathrm{wt} \%$ HFBII, mixers 1 and 2; formation of non-spherical bubbles is observed in the latter case.

Fig. 2 compares results for the bubble size distribution for (i) foams produced only by mixer 1 and (ii) foams produced by consecutive use of mixers 1 and 2, all other conditions being the same: $0.7 \mathrm{wt} \% \mathrm{HFBII}$ and $\mathrm{pH}=6$. By using semi-automatic image analysis, we measured the radii of 320 and 1367 bubbles, respectively, for Figs. 2a and 2c. The points in these figures 
represent the cumulative function $f$ directly determined from the experimental data using Eq. (6). The solid lines represent the best fits with Eq. (8). The excellent agreement between the theoretical curve and the data indicates that the bubble size in the foams obeys the lognormal distribution. This holds for all foams investigated in the present study.

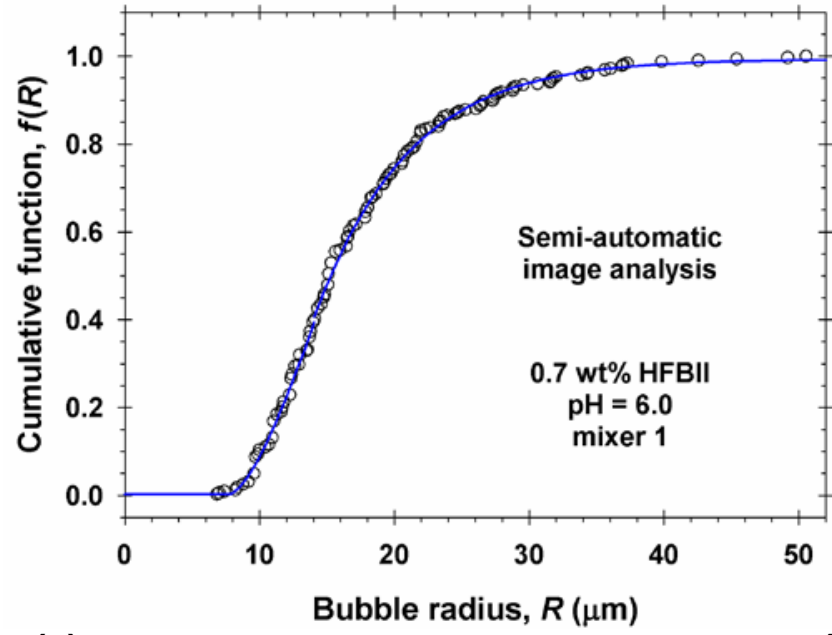

(a)

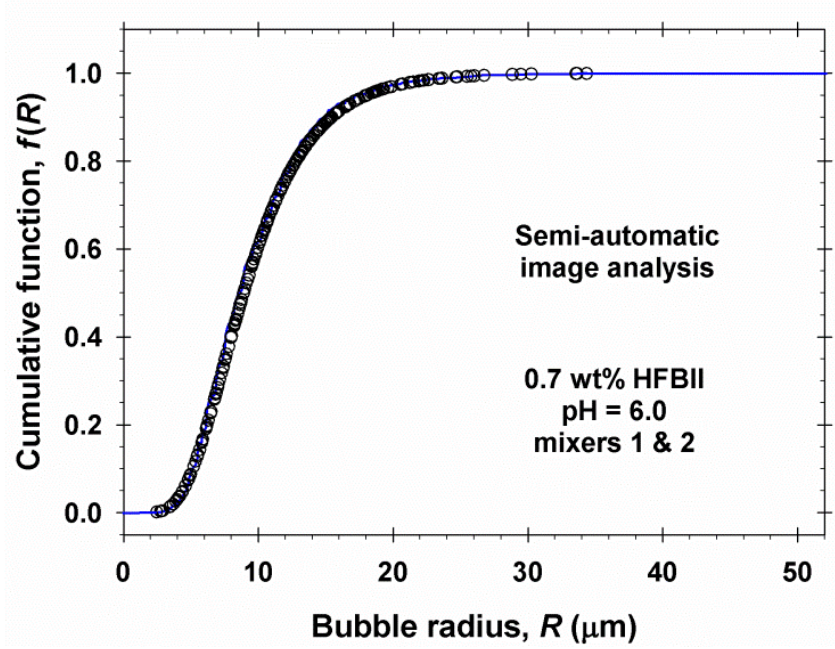

(c)

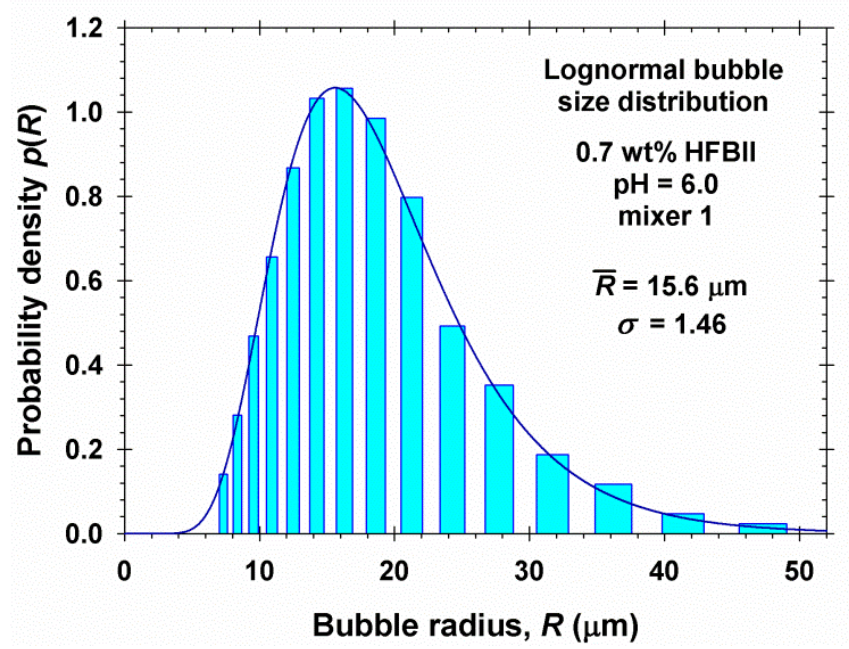

(b)

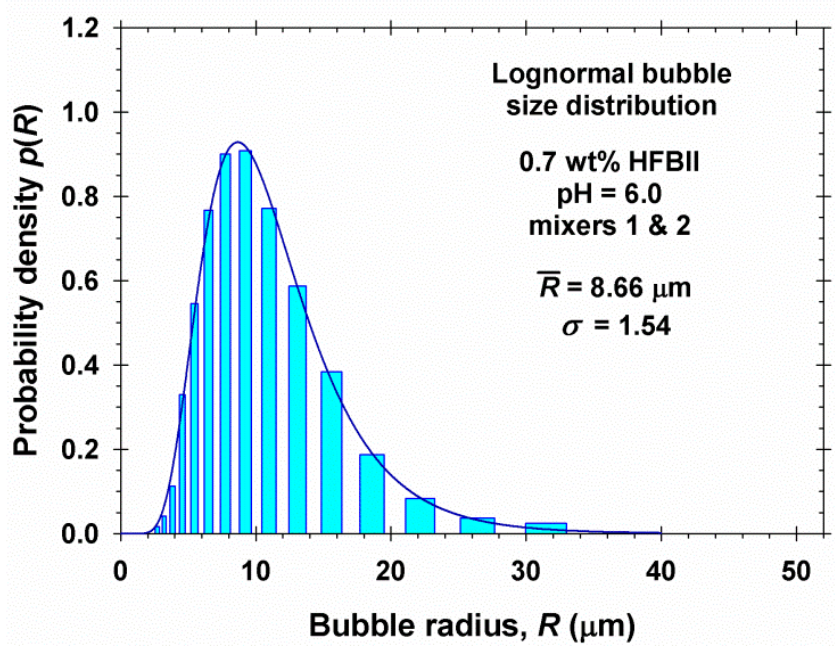

(d)

Fig. 2. Initial experimental bubble size distributions in foams from solutions of $0.7 \mathrm{wt} \% \mathrm{HFBII}$ at the natural $\mathrm{pH}=6.0$ obtained by semiautomatic image analysis. (a,b) Foam prepared by stirring with mixer 1 for $60 \mathrm{~s}$. (c,d) Foam prepared by stirring with mixer 1 for $60 \mathrm{~s}$ and mixer 2 for $60 \mathrm{~s}$. The points are experimental data for the cumulative function $f(R)$; the solid line for $f(R)$ is the best fit of the data with Eq. (8); the solid line for $p(R)$ is calculated from Eq. (7) using the values of $\bar{R}$ and $\sigma$ determined from the best fit. 
The values of the parameters $\sigma$ and $\bar{R}$ determined from the fits in Figs. 2a and 2c are shown in Table 1 . The most probable radius of the lognormal bubble size distribution, $\bar{R}$, is close, but slightly lower, than the mean arithmetic bubble radius $R_{10}$. The mean radius of the lognormal distribution, which is given by the formula $\langle R\rangle=\bar{R} \exp \left(\frac{1}{2} \ln ^{2} \sigma\right)$ [56,57], practically coincides with $R_{10}$, as is should be expected in the case of good agreement between the theoretical curve and the experimental data. The volume-to-surface mean radius, $R_{32}$, is with about $40 \%$ larger than $R_{10}$, which is due to the essential contribution of the bigger bubbles to $R_{32}$. The difference between these characteristic mean radii is due to the polydispersity of the bubbles. The values of the dimensionless dispersion, $\sigma$, are close for the two systems (Table 1).

Table 1. Comparison of $\sigma, \bar{R}$ and $\langle R\rangle$ determined from the fits in Figs. 2a,c with $R_{10}$ and $R_{32}$ directly determined from the experimental data according to Eq. (3).

\begin{tabular}{|l|c|c|c|c|c|}
\hline System & $\sigma$ & $\bar{R}(\mu \mathrm{m})$ & $\langle R\rangle(\mu \mathrm{m})$ & $R_{10}(\mu \mathrm{m})$ & $R_{32}(\mu \mathrm{m})$ \\
\hline Foam with mixer 1 & 1.46 & 15.6 & 16.8 & 17.2 & 24.2 \\
\hline Foam with mixers 1 \& 2 & 1.54 & 8.7 & 9.6 & 9.6 & 13.9 \\
\hline
\end{tabular}

The bubble polydispersity is better illustrated in Figs. 2b,d, where the bubble size distributions are presented. It is well visible that the use of second mixer leads to the formation of smaller bubbles. For Fig. 2b, $50 \%$ of the bubbles belong to the interval $10.7<R<22.5 \mu \mathrm{m}$, whereas for Fig. $2 \mathrm{~d}$ the respective interval is $5.63<R<13.3 \mu \mathrm{m}$. The solid lines are the probability density functions, $p(R)$, calculated from Eq. (7) using the values of $\sigma$ and $\bar{R}$ in Table 1 . Note that if $p(R)$ is plotted vs. $\ln R$ (rather than vs. $R$ ) the bubble size distributions will be symmetric; the bars of the histograms will have the same width, and the area below each probability curve will be equal to 1; see Eq. (8). Note also that the theoretical curves in Figs. $2 \mathrm{~b}$,d, determined from the cumulative functions, are unique, whereas the presentation of the data as histogram is not unique, but depends on the choice of the width of the bars.

\subsection{Foaminess}

To characterize the foaminess of the hydrophobin solutions, in Fig. 3a we show plots of experimental data for the foam overrun vs. the HFBII concentration at the initial moment, just after the foam generation. The overrun is calculated from Eq. (2) using the experimental gas 
volume fraction, $\Phi$, determined just after the foam generation (at $t=0$ ). For all investigated $\mathrm{pH}$ values, the overrun is between 4 and 8 for the foams generated by mixers 1 and 2, whereas it is in the range between 2.0 and 4.6 for the foam produced by mixer 1 alone. The overrun is slightly higher for the foams prepared at $\mathrm{pH}=4.3$ as well as at $\mathrm{pH}=6$ for the lower HFBII concentrations. This could be explained with the higher fluidity of the bubble surfaces at the lower hydrophobin concentrations [31], which allows a fast regeneration of the protein adsorption layer upon splitting the bigger bubbles to smaller ones by the stirrer.

In contrast, at higher HFBII concentrations rigid protein adsorption layers are formed, which are broken upon splitting the bubbles and are unable to protect the newly formed bubbles against coalescence. In a final reckoning, this hampers the uptake of air in the foam and reduces the foaminess. It should be noted that the left end of each experimental curve in Fig. 3a corresponds to the lowest hydrophobin concentration, at which stable foam was produced.

The gas volume fraction $\Phi$ in the studied foams is in the range between 0.69 and 0.90 ; see Appendix D. These relatively high values of $\Phi$ can be due to bubble deformations [59]; polydispersity [60], and elongated shape. Note that HFBII is able to stabilize not only $\mu \mathrm{m}$-sized, but also submicron bubbles [45]. The latter are not visible in our photographs, but influence the measured weight of the foam. The photographs in Fig. 1 with rounded bubbles represent only the uppermost foam layer. However, in the depth of the foam the bubbles are expected to be deformed pressed by their neighbors and hydrostatic pressure.

Fig. 3b shows plots of $R_{32}$, vs. the HFBII concentration obtained by image analysis. Some irregularities in the shape of the experimental curves could be attributed to the effect of rupturing of the solidified protein adsorption layers on the bubble surfaces by the mixer. The strong rise of $R_{32}$ at $\mathrm{pH}=6$ (near the isoelectric point of HFBII) for the lower HFBII concentrations could be explained with limited bubble coalescence, which is analogous to that observed with drops in the Pickering emulsions; see e.g. [51,54,61,62]. Excluding this special case, all data for $R_{32}$ in Fig. 3b belong to the interval between 5 and $40 \mu \mathrm{m}$, which corresponds to foams with fine bubbles. This fact indicates that the foaming process used in our experiments leads to the production of smaller bubbles as compared to those obtained in Ref. [9], where $R_{10}$ in the range between 57 and 118 $\mu \mathrm{m}$ has been measured. In both cases, the foam was prepared by mixer, but in our case the input of mechanical energy per unit volume was greater. Indeed, the volume of the aerated liquid was $75 \mathrm{~mL}$ in Ref. [9], vs. only $3 \mathrm{~mL}$ in our experiments. 
(a)

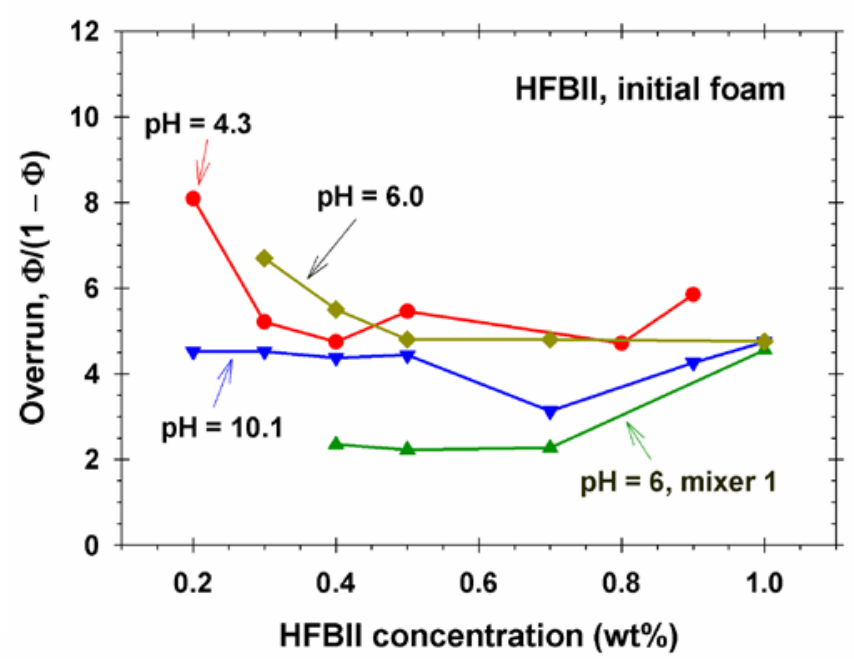

(b)

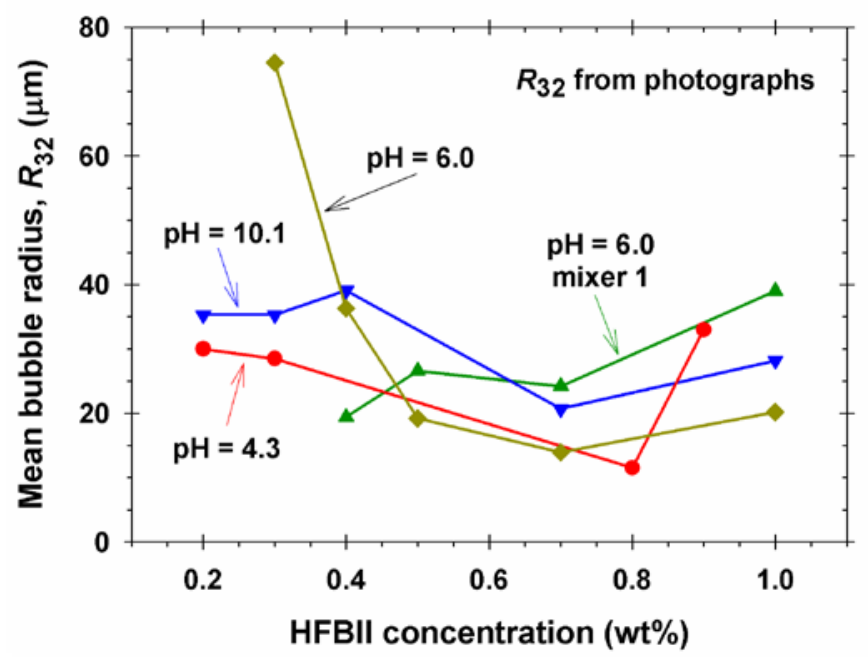

(c)

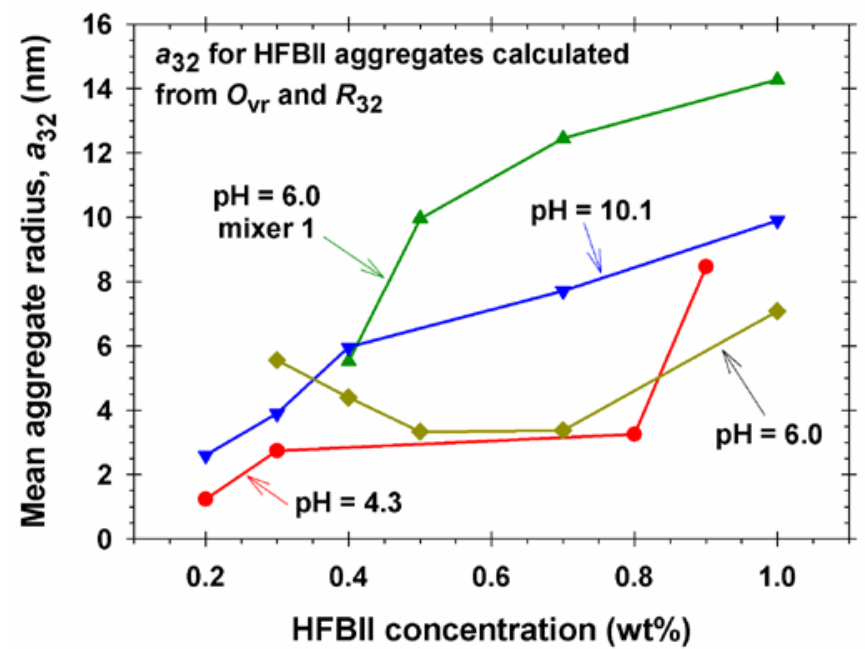

Fig. 3. Characterization of foaminess. Plots of (a) the foam overrun, $\Phi /(1-\Phi)$; (b) the mean bubble radius, $R_{32}$, and (c) the mean radius of the adsorbed HFBII aggregates, $a_{32}$, vs. the HFBII concentration; details in the text. The lines are guides to the eye. 
Fig. 3c shows values of the mean radius of the protein aggregates, $a_{32}$, adsorbed on the bubble surfaces; $a_{32}$ is calculated from Eq. (4), where the values of the overrun and $R_{32}$ from Figs. 3a,b have been substituted. For a dense protein adsorption layer, we have set $\varphi_{\mathrm{a}} \approx 1$ and $\rho_{\mathrm{p}}$ $=1.5 \mathrm{~g} / \mathrm{cm}^{3}$, estimated from the empirical dependence in Ref. [63]. Despite some scattering of the data, there is a tendency for $a_{32}$ to increase with the rise of HFBII concentration (Fig. 3c), which is a physically reasonable result. The smallest values of $a_{32}$, close to the radius of the HFBII molecule, $\approx 1.5 \mathrm{~nm}$, are obtained at $\mathrm{pH}=4.3$, at which the HFBII molecules acquire positive electric charge [45]. In contrast, $a_{32}$ is the greatest (the adsorbed aggregates are the biggest) at the isoelectric point $(\mathrm{pH} \approx 6.0)$, in the case where mixer 1 has been only used. It seems that a longer agitation (with mixers 1 and 2) helps for deposition of thinner HFBII layers on the bubble surfaces. The scattering of the data in Fig. 3, which is typical for foams with hydrophobin (see below), could be due not only to the breakage of the formed rigid adsorption layers on the bubble surfaces, but also to uncontrollable growth of protein aggregates in the stirred dispersion.

\subsection{Foam stability}

To characterize the foam stability, the syringes with the investigated foams were kept for 17 days in a refrigerator at $4{ }^{\circ} \mathrm{C}$, and then the foam volume, $V_{\mathrm{F}}$, and weight, $G_{\mathrm{F}}$, was measured again, as explained in Section 2. We observed some changes in $V_{\mathrm{F}}$ and $G_{\mathrm{F}}$ only during the first three days. A small amount of water drained below the foam, and/or the volume of the foam shrinks, probably due to contraction of the elastic hydrophobin layers. We did not observe any further changes in the state of these foams after the third day of storage. In other words, all these hydrophobin stabilized foams are rather stable. The changes during the first days consisted in the release of a small amount of water below the foam and/or formation of small cavities in the foam. The fact that these changes happen in a limited period of time implies that they are most probably due to limited bubble coalescence like that in Pickering emulsions [51,54,61,62]; see Appendix B for details. Samples of the foam have not been taken from the syringe for optical observations (to investigate the evolution of bubble size distribution) because any mechanical impact on the aged foam leads to structural changes. 
Fig. 4 shows plots of $V_{\mathrm{F}}(t) / V_{\mathrm{F}}(0)$ and $G_{\mathrm{F}}(t) / G_{\mathrm{F}}(0)$ vs. the HFBII concentration $(t=17$ days). The experimental curves have kinks, which are typical for foams with solidifying protein adsorption layers, for which the stirring produces two opposite effects: (i) bubble generation and (ii) bubble coalescence due to rupturing of solidified adsorption layers. Moreover, the protein aggregates present in such solutions could also play two opposite roles: (i) foam-stabilizers when they serve as "spacers" separating the two film surfaces and (ii) antifoam particles when they enter the film surfaces and cause film rupture by the bridging or spreading mechanisms $[64,65]$. The competition of these opposite tendencies leads to fluctuations in the initial foam volume and in the limited bubble coalescence that goes during the first there days of foam storage; see Appendix B. Nevertheless, the data indicate the existence of several tendencies. Both $V_{\mathrm{F}}(t) / V_{\mathrm{F}}(0)$ and $G_{\mathrm{F}}(t) / G_{\mathrm{F}}(0)$ are lower when only mixer 1 , has been used to generate the foam. The relative foam volume, $V_{\mathrm{F}}(t) / V_{\mathrm{F}}(0)$, is greater $(\geq 80 \%)$ at $\mathrm{pH}=4.3$ and 6.0 , whereas the retention of water in the foam, $G_{\mathrm{F}}(t) / G_{\mathrm{F}}(0)$, is greater $(\geq 80 \%)$ at $\mathrm{pH}=10.1$ and 6.0. For all investigated foams $V_{\mathrm{F}}(t) / V_{\mathrm{F}}(0) \geq 67 \%$, whereas $G_{\mathrm{F}}(t) / G_{\mathrm{F}}(0) \geq 50 \%$, which indicates a high longevity of the produced foams in view of the relatively long period of foam storage (17 days).

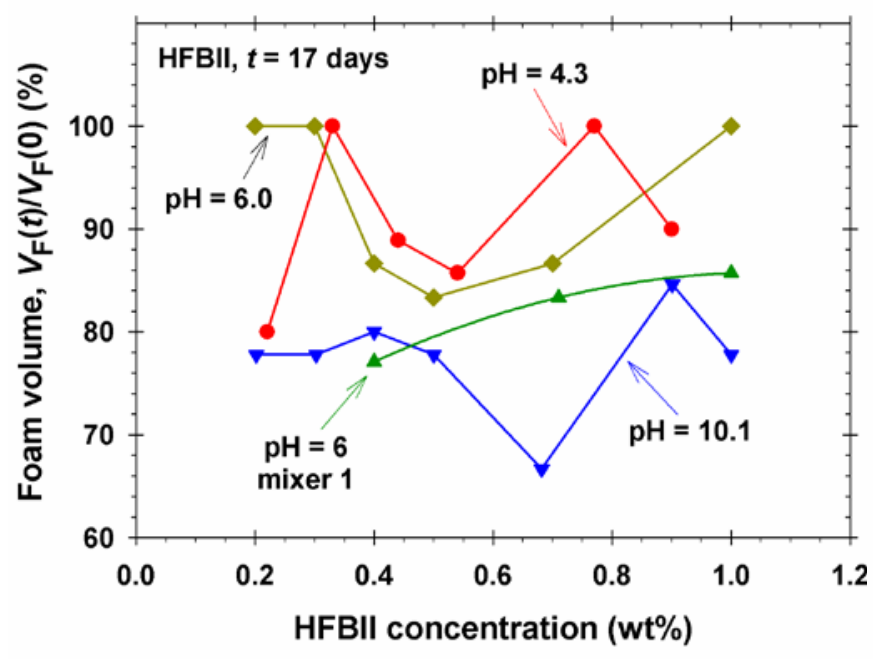

(a)

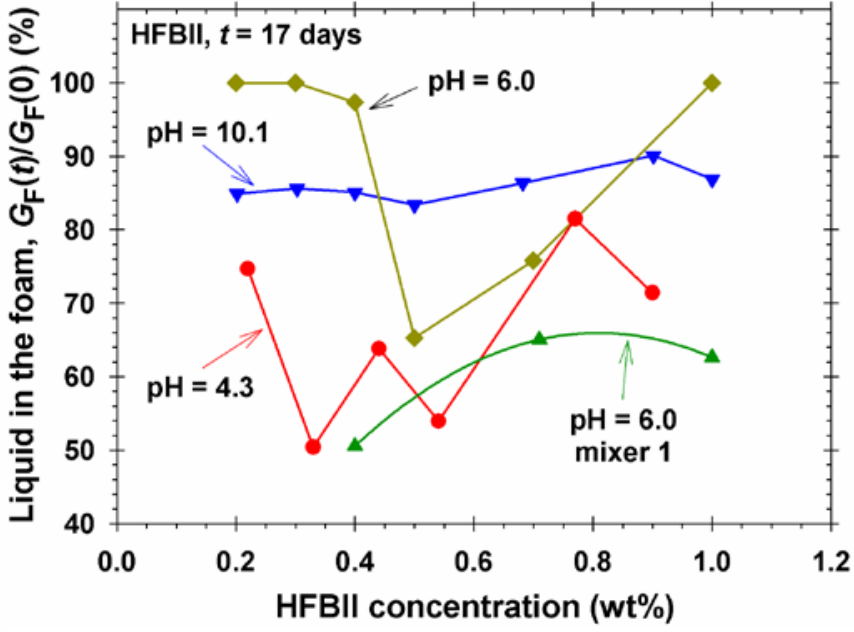

(b)

Fig. 4. Characterization of foam stability with data for foams at $t=17$ days after their formation. (a) Foam volume, $V_{\mathrm{F}}(t)$ scaled with the initial foam volume, $V_{\mathrm{F}}(0)$, vs. the HFBII concentration. (b) Weight of the liquid (water) in the foam, $G_{\mathrm{F}}(t)$, scaled with the initial weight, $G_{\mathrm{F}}(0)$, vs. the total HFBII concentration. The lines are guides to the eye. 
To characterize the foam stability with a single number, we propose a combined criterion (indicator), viz. the degree of foam conservation, $D_{\mathrm{FC}}$, defined as follows:

$$
D_{\mathrm{FC}}(t)=3 \times\left(\frac{V_{\mathrm{F}}(t)}{V_{\mathrm{F}}(0)}+\frac{G_{\mathrm{F}}(t)}{G_{\mathrm{F}}(0)}\right)
$$

$D_{\mathrm{FC}}(t)$ is calculated using experimental data for $V_{\mathrm{F}}(t)$ and $G_{\mathrm{F}}(t)$, like those in Fig. 4. The normalizing factor 3 in Eq. (9) is chosen in such a way to give $D_{\mathrm{FC}}=6$ for an excellent conservation of the foam, i.e. $V_{\mathrm{F}}(t) / V_{\mathrm{F}}(0)=1$ and $G_{\mathrm{F}}(t) / G_{\mathrm{F}}(0)=1$ (no changes in the foam volume and weight after foam storage for a period of time $t$ ). The other grades are $D_{\mathrm{FC}}=5,4,3$, and 2, respectively, for very good, good, satisfactory, and poor conservation of the foam; see Fig. 5.

In Fig. $5 \mathrm{a}$, the best $\left(D_{\mathrm{FC}}>5\right)$ are the foams at $\mathrm{pH}=6$, close to the isoelectric point for bubbles, which is at $\mathrm{pH}=5.8$ (determined by us from the electrophoretic mobility of bubbles in HFBII solutions). At $\mathrm{pH}=4.8$ and 10.1, the degree of foam conservation is slightly lower: $4.2 \leq D_{\mathrm{FC}} \leq 5.4$. $D_{\mathrm{FC}}$ is the lowest for the foam prepared with one mixer only. The variation of $\mathrm{pH}$ produces a weak effect on foaminess, which is in agreement with previous findings that $\mathrm{pH}$ does not essentially affect the hydrophobin adsorption [47] and the surface forces in HFBII stabilized films [46].

For comparison, in Fig. 5b, we show data for the stability of the foams from mixed solutions of HFBII with three other proteins, BLG, BSA and OVA after a storage time of $t=12$ days. The concentration of HFBII was varied, whereas the concentration of the other protein was fixed at $0.5 \mathrm{wt} \%$. More details for the foaminess of these mixed solutions can be found in Section 4. Here, we have to note only that the stability of the respective foams, characterized by $D_{\mathrm{FC}}$, is comparable with that in the case of HFBII alone. This stability (durability longer than 12 days) is entirely due to the presence of hydrophobin. Indeed, the foams stabilized with BLG, BSA or OVA, alone (at the same total protein concentrations), undergo an intensive Ostwald ripening (foam disproportionation), which leads to their complete destruction within $1-2$ hours. This comparison indicates that the main stabilizing property of hydrophobin as foaming agent is that it almost completely blocks the Ostwald ripening of foams. This could be explained with the formation of dense hydrophobin adsorption layers, which are impermeable to the transfer of gas. 
(a)

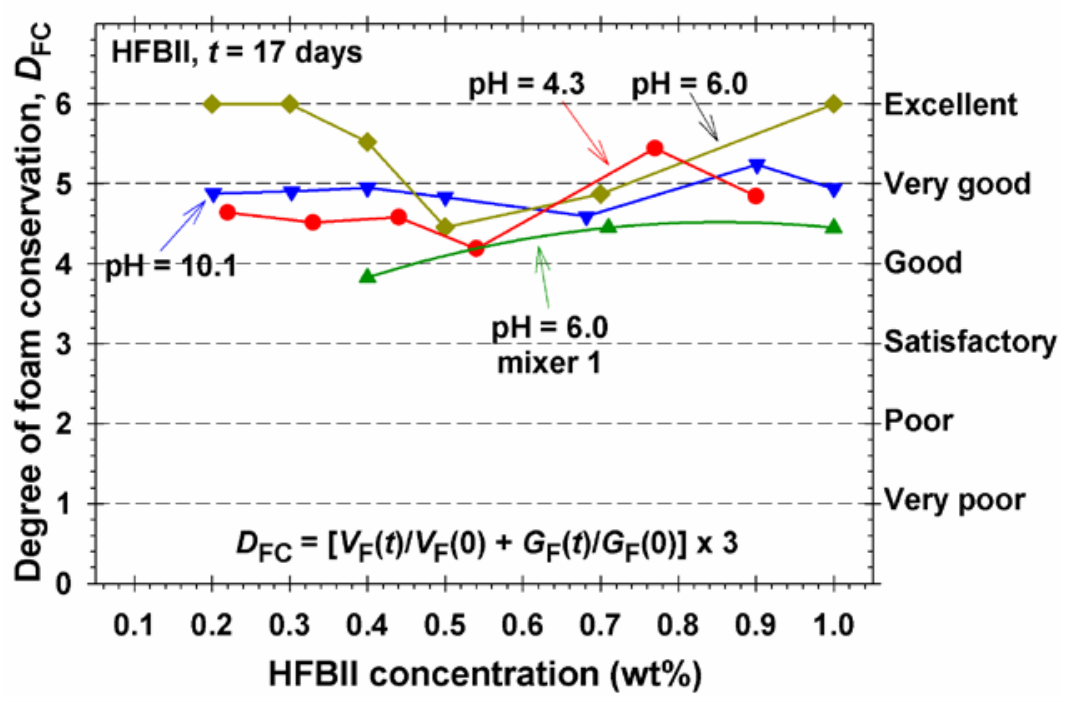

(b)

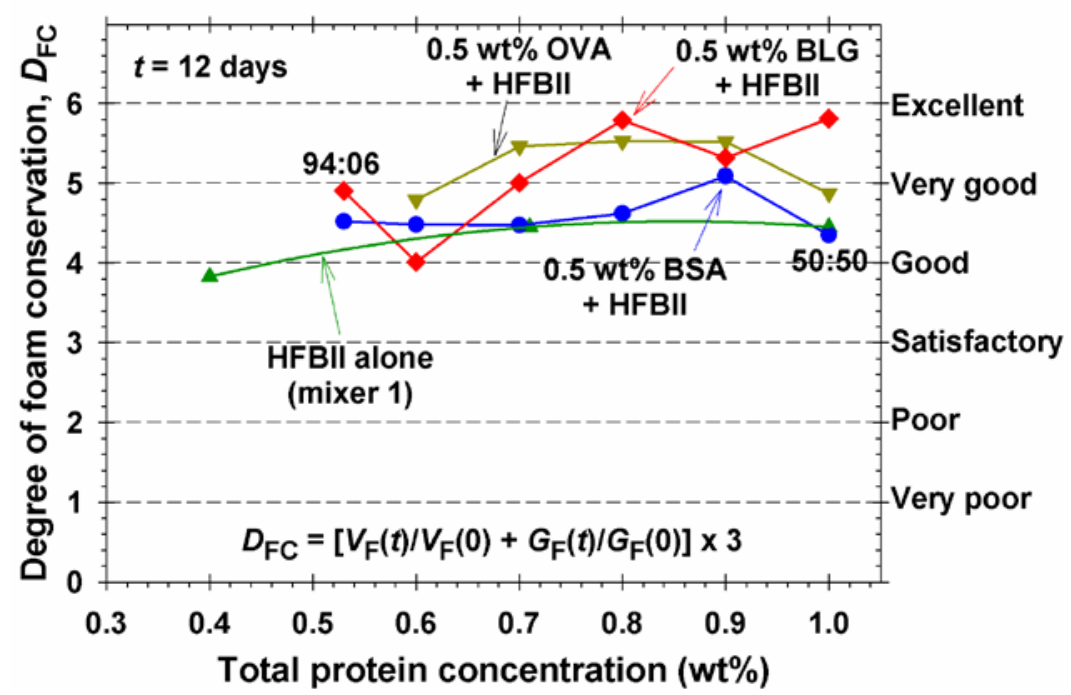

Fig. 5. Degree of foam conservation, $D_{\mathrm{FC}}$, vs. the total protein concentration: (a) Foams of age $t=$ 17 days from solutions of HFBII at various pH. (b) Foams of age $t=12$ days from solutions of HFBII with added $0.5 \mathrm{wt} \%$ regular protein (BLG, OVA or BSA). The lines are guides to the eye.

In addition, as seen in Fig. 4b the hydrophobin suppresses also the drainage of liquid out of the foam. Insofar as the liquid drains along the Plateau borders, the suppression of foam drainage means that HFBII possesses the property to block the Plateau borders. It is known that hydrophobins stabilize bubbles of micrometer and submicron size [45,66]. This can be easily observed by shaking a test tube with a transparent HFBII solution, which immediately becomes turbid due to the formed microscopic bubbles. Such tiny bubbles ( $\mu$ m-sized and smaller) appear also in the investigated foams owing to the intensive stirring with the mixers during the process 
of foam generation. Because HFBII is a "sticky" protein [46], the miniature bubbles adhere to the walls of the Plateau borders and block the drainage of water, as illustrated in Fig. 6a. Because the consecutive stirring with mixers 1 and 2 produces more tiny bubbles (see e.g. Fig. 6b) than the stirring with mixer 1 only, in the latter case the foams exhibit a lower degree of foam conservation; see Fig. 5. In addition, the narrower channels between the smaller bubbles can be blocked by protein aggregates, which are able to suppress the drainage (syneresis) of proteinstabilized foams $[12,67,68]$.

(a)

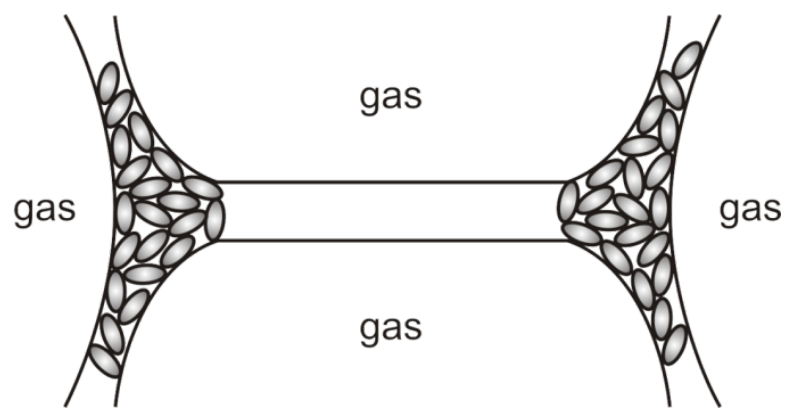

(b)

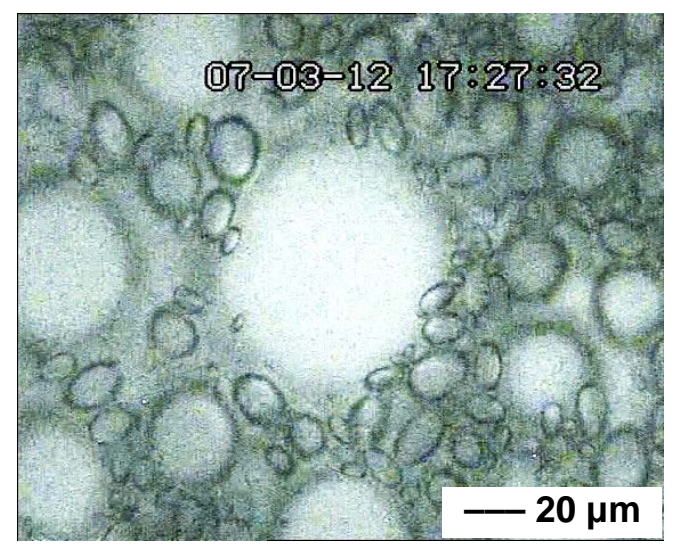

Fig. 6. (a) Sketch of small bubbles that fill and block the Plateau borders in the foam. (b) Photograph of big and small bubbles in a foam produced from a solution of $0.5 \mathrm{wt} \% \mathrm{HFBII}+$ 0.5 wt\% OVA by using mixers 1 and 2 .

\section{Foams from mixed solutions of HFBII with other proteins}

For brevity, we will call proteins like BLG, BSA and OVA “regular proteins” (RP). Most of the proteins, like BLG, BSA and OVA, are not good foaming agents - the foams produced from their solutions are relatively unstable. In Appendix $C$ this is illustrated by data for the dynamics of coarsening of foams from solutions of these proteins at a concentration of 0.5 wt $\%$ 
(the same as in Figs. 1c,d) - continuous increase of the mean bubble radius is observed with an average growth rate between 158 and $321 \mu \mathrm{m} / \mathrm{h}$. The prism method by Garrett et al. was used; see Refs. [69-72]. In all cases, the foams produced from solutions of regular proteins completely decayed within 2.5 - 3.5 hours. In contrast, for such period of time, the foams produced from HFBII solutions did not undergo any noticeable changes; see details in Appendix C.

Here, our goal is to investigate whether it is possible to replace a part of hydrophobin with a regular protein without essentially reducing the solutions' foaminess and the foam stability. Foams from the mixed protein solutions were produced in the same way and look very similar to those from solutions of HFBII without additives; see, e.g., Figs. 1 and 6b. Again, the bubble size distributions obey the longnormal distribution (Fig. 2). For this reason, below we focus our attention on the foaminess and foam stability.

\subsection{Foaminess of the mixed protein solutions}

In all experiments with mixed solutions, the concentration of the regular protein was fixed to $0.5 \mathrm{wt} \%$, whereas the concentration of HFBII was varied. The measurements were carried out at the solutions' natural $\mathrm{pH}$, which is about 6. The $\mathrm{pH}$ of the mixed protein solutions was measured - it was in the interval $5.5<\mathrm{pH}<6.5$. These relatively small variations are not expected to essentially influence the protein interactions and foam properties. Indeed, the stability

of the foams from the mixed solutions is governed by HFBII, but it is known that $\mathrm{pH}$ does not essentially affect the hydrophobin adsorption [47] and the surface forces in HFBII stabilized films [46]. The highest used hydrophobin concentration was $0.5 \mathrm{wt} \%$, which corresponds to 50:50 RP/HFBII weight ratio; see Fig. 7. Furthermore, the concentration of HFBII in the mixed solutions was decreased, until reaching the region of unstable foams. For each experimental curve in Fig. 7, the leftmost point corresponds to the last observed stable foam. For the foams with BLG and BSA, the leftmost point corresponds to a weight ratio of 94:06 RP/HFBII. At lower fractions of HFBII, the foaminess and foam stability strongly decrease.

Fig. 7a presents experimental data for the foam overrun plotted versus the total protein concentration. The data show that in a wide interval of protein concentrations the overrun is practically constant, between 4 and 7, which is the same range as for HFBII alone (Fig. 3a). The latter fact indicates that the foaminess of the mixed solutions is dominated by the hydrophobin. 
(a)

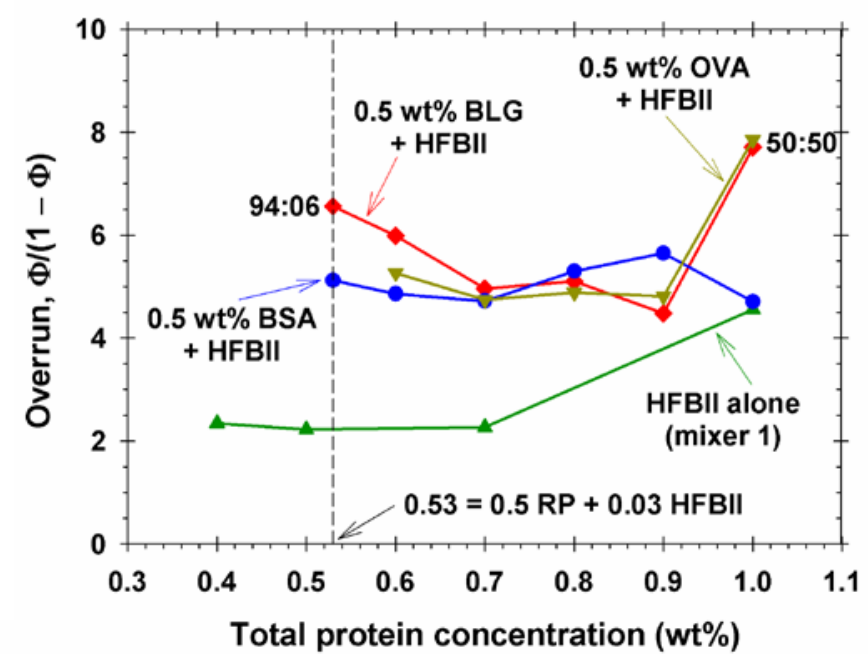

(b)
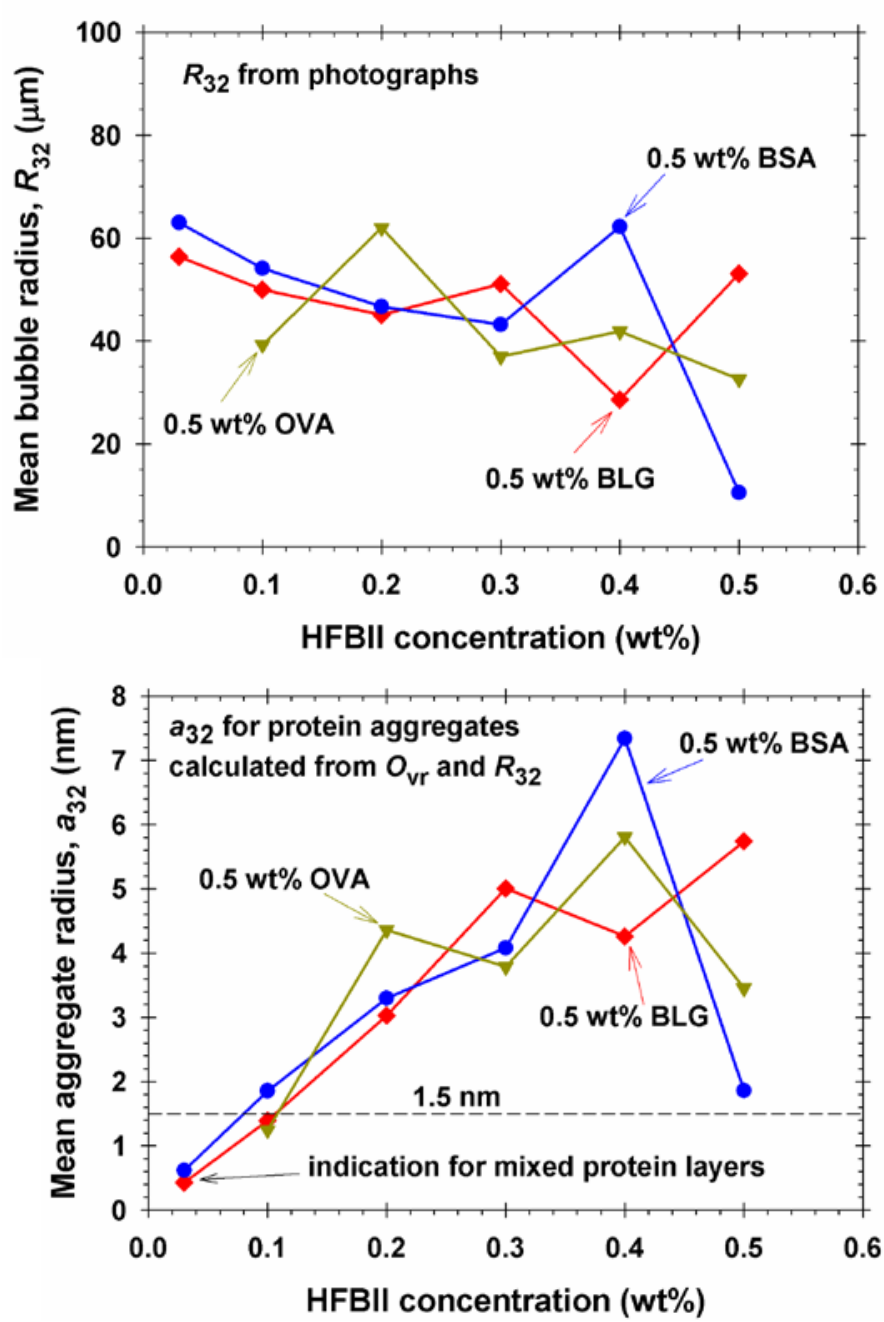

Fig. 7. Characterization of foaminess. The concentration of regular protein (BLG, OVA or BSA) is fixed to $0.5 \mathrm{wt} \%$, whereas the concentration of HFBII is varied. (a) The foam overrun, $\Phi /(1-\Phi)$, vs. the total protein concentration. (b) The mean bubble radius, $R_{32}$, vs. the HFBII concentration. (c) The mean radius of the protein aggregates, $a_{32}$, vs. the HFBII concentration; details in the text. The lines are guides to the eye. 
For the mixed solutions with BSA, the overrun is almost constant. For the mixed solutions with BLG and OVA a greater overrun, about 8, has been registered at 50:50 RP/HFBII weight ratio. All foams from the mixed solutions have been prepared by consecutive use of mixers 1 and 2 . The overrun of these foams is greater than that of the foams from HFBII solutions obtained by using only mixer 1 (Fig. 7a). The gas volume fraction $\Phi$ in the studied foams is in the range between 0.69 and 0.89; see Appendix D.

Fig. 7b shows plots of the volume-to-surface mean radius $R_{32}$ vs. the HFBII concentration in the mixed solutions. The experimental points are obtained from photos of the foam by image analysis; see Eq. (3). For the different regular proteins, the obtained $R_{32}$ values are close to each other and exhibit a tendency to decrease from ca. 60 to $30 \mu \mathrm{m}$ with the rise of HFBII concentration. As in the case of HFBII without additives, the produced foams have fine bubbles.

In Fig. 7c, we have plotted the mean radius of the protein aggregates, $a_{32}$, calculated from Eq. (4), where the values of the overrun and $R_{32}$ from Figs. 7a,b have been substituted. As before, the values $\varphi_{\mathrm{a}}=1$ and $\rho_{\mathrm{p}}=1.5 \mathrm{~g} / \mathrm{cm}^{3}$ have been used. The investigations with thin liquid films and surface shear rheology of adsorption layers from mixed solutions of HFBII with BLG and OVA [28], showed that the more surface active HFBII occupies the air/water interface, whereas the other globular protein forms a second layer, as illustrated for BLG in Fig. 8a. (Probably, the BLG molecules are attached to the interfacial hydrophobin layer at the openings of their hydrophobic pockets [73], as sketched in Fig. 8a.) For this reason, to estimate $a_{32}$ in Eq. (4) we have substituted $w_{\mathrm{p}}=$ weight concentration of HFBII, so that the assumption that the whole amount of protein has been adsorbed on the bubbles holds only for the hydrophobin. The obtained values of $a_{32}$ (Fig. 7c) are reasonable, except the leftmost points, for which $a_{32}$ is smaller than the radius of the HFBII molecule, $1.5 \mathrm{~nm}$. This indicates the formation of a mixed adsorption layer of HFBII and the regular protein as sketched in Fig. 8b. For the configuration in Fig. 8b, $w_{\mathrm{p}}$ in Eq. (4) should include not only the HFBII concentration, but also a fraction of the other protein (e.g. BLG), and then the calculated $a_{32}$ would be greater; see Eq. (4). It is remarkable that the analysis of data for a macroscopic quantity, like the overrun (Fig. 7a), could provide structural information for the adsorption layers; compare Figs. 8a and 8b. 
(a)

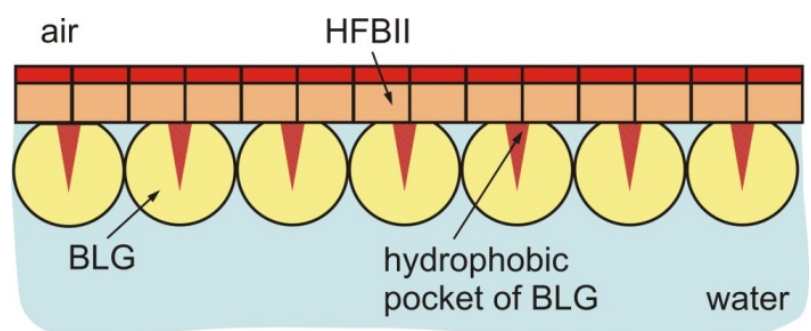

(b)

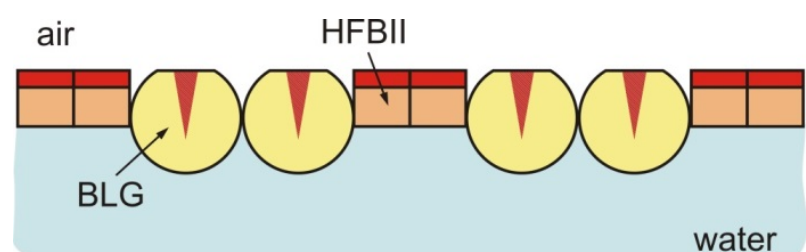

Fig. 8. (a) At sufficiently high HFBII concentrations, the hydrophobin makes a dense layer at the air/water interface and the regular protein (in this case BLG) adsorbs below it. (b) At lower HFBII concentrations, a mixed adsorption layer of the two proteins is formed. The hydrophobic and hydrophilic parts of the HFBII molecules are shown by different colors to schematically present their character of Janus-like particles.

\subsection{Stability of the foams from mixed protein solutions}

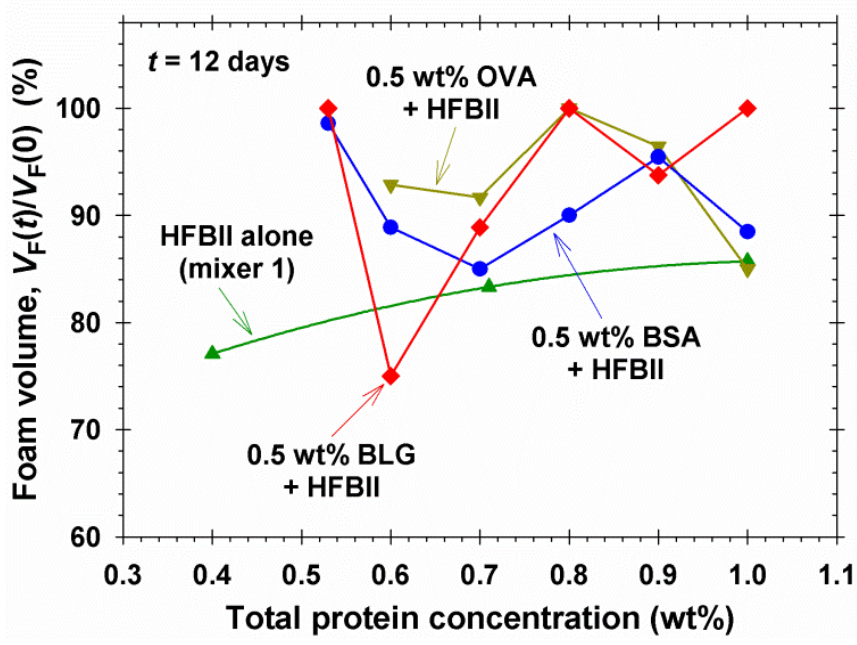

(a)

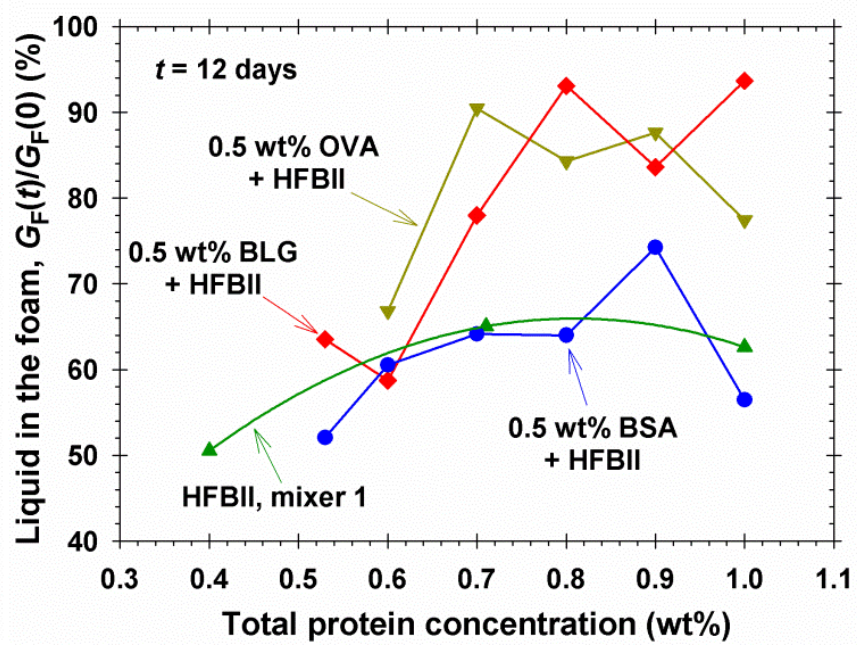

(b)

Fig. 9. Characterization of foam stability with data for foams at $t=12$ days after their formation. (a) Foam volume, $V_{\mathrm{F}}(t)$ scaled with the initial foam volume, $V_{\mathrm{F}}(0)$, vs. the total protein concentration (HFBII + regular protein). (b) Weight of the liquid (water) in the foam, $G_{\mathrm{F}}(t)$, scaled with the initial weight $G_{\mathrm{F}}(0)$, vs. the total protein concentration. The concentration of regular protein (BLG, BSA or OVA) is fixed to $0.5 \mathrm{wt} \%$, whereas the concentration of HFBII varies. 
Fig. 9a shows a plot of the foam volume $V_{\mathrm{F}}(t)$, at $t=12$ days after the foam formation, scaled with the initial foam volume, $V_{\mathrm{F}}(0)$. As in the case of HFBII without additives, the data indicate that $V_{\mathrm{F}}(t)$ is almost constant for $t \geq 3$ days. The values of $V_{\mathrm{F}}$ are comparable for BLG, BSA and OVA. $V_{\mathrm{F}}(t)$ is greater in the case of two mixing stages. The changes with the foam, which occur during the first three days of storage, are described in Appendix B, Table B.3.

(a)

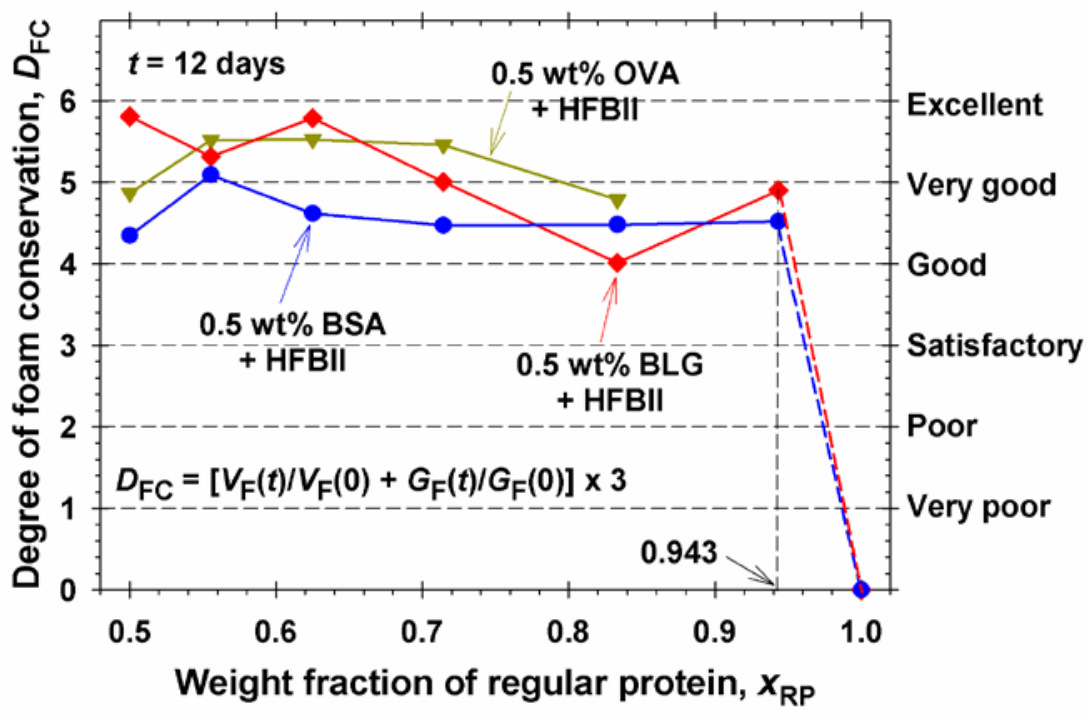

(b)

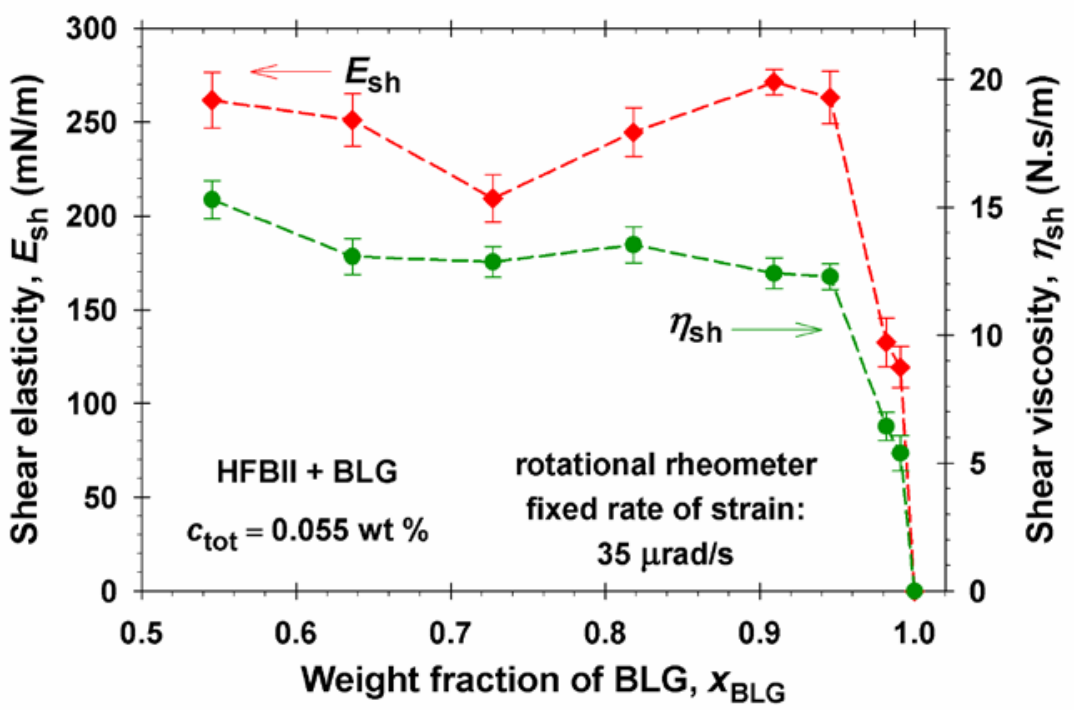

Fig. 10. Effect of composition on the degree of foam conservation, $D_{\mathrm{FC}}$, and on the shear elasticity and viscosity of the protein adsorption layer, $E_{\mathrm{sh}}$ and $\eta_{\mathrm{sh}}$. (a) The data for $D_{\mathrm{FC}}$ from Fig. $5 \mathrm{~b}$ plotted vs. the weight fraction of the regular protein (BLG, BSA or OVA), $x_{\mathrm{RP}}$. (b) Data from Ref. [28] for $E_{\text {sh }}$ and $\eta_{\text {sh }}$ of mixed HFBII + BLG adsorption layers plotted vs. the weight fraction of BLG, $x_{\mathrm{BLG}}$, at a fixed total protein concentration, $c_{\mathrm{tot}}=0.055 \mathrm{wt} \%$. 
Figure 9b shows a plot of the foam weight $G_{\mathrm{F}}(t)$ at $t=12$ days after the foam formation scaled with the initial foam weight, $G_{\mathrm{F}}(0) . G_{\mathrm{F}}(t)$ is the weight of water in the foam, and its diminishing indicates drainage of water from the foam. $G_{\mathrm{F}}$ is greater for BLG and OVA at HFBII concentrations $\geq 0.2 \mathrm{wt} \%$ (i.e. total protein concentrations $\geq 0.7 \mathrm{wt} \%$ ). $G_{\mathrm{F}}$ is smaller for BSA. As a rule, $G_{F}(t)$ is greater in case of two mixing stages.

In Fig. 10a, the degree of foam conservation $D_{\mathrm{FC}}(t)$ is calculated from the data in Fig. 9 by using Eq. (9). In fact, Fig. 10a contains the same data as Fig. 5b, but plotted vs. the weight fraction of the regular protein, $x_{\mathrm{RP}}$. For $0.5 \leq x_{\mathrm{RP}} \leq 0.943$, the data points correspond to stable foams. The highest stability (points with $D_{\mathrm{FC}}>5$ ) is observed for foams with BLG and OVA. It turns out that we can replace up to $94 \%$ of HFBII with RP, without a significant deterioration of foam quality and stability. However, for $x_{\mathrm{RP}}>0.943$ no stable foams have been obtained.

The purpose of this figure is to visualize the correlation of the foam stability (Fig. 10a) with the surface shear elasticity and viscosity, $E_{\mathrm{sh}}$ and $\eta_{\mathrm{sh}}$, of mixed (HFBII + BLG) adsorption layers (Fig. 10b) determined in Ref. [28]. In the rheological experiments, a rotational rheometer Bohlin Gemini (Malvern Instruments, UK) was used at a low constant angular velocity of $35 \mu \mathrm{rad} / \mathrm{s}$. The sensitivity of this rheometer is appropriate for measurements with highly elastic adsorption layers containing hydrophobin, but for measurements with regular proteins (without hydrophobin) more sensitive rheometers should be used; see $[10,74,75]$. Mixed solutions of HFBII and BLG were investigated at various weight fractions of BLG in the range $0.5 \leq x_{\mathrm{BLG}} \leq 1$, but at fixed total protein concentration of $0.055 \mathrm{wt} \%$. At $x_{\mathrm{BLG}}=1$, no rheological response was registered, which means that both $E_{\text {sh }}$ and $\eta_{\text {sh }}$ are equal to zero (undetectable by the used rheometer) in the absence of HFBII. The data show that the transition from elastic to fluid adsorption layers occurs at $x_{\mathrm{BLG}}$ $\approx 0.94$ (Fig. 10b) and it excellently correlates with the foam stability (Fig. 10a).

From a structural viewpoint, we could suppose that at $0 \leq x_{\mathrm{BLG}} \leq 0.94$ the more surface active HFBII occupies the air/water interface and forms a rigid adsorption layer, whereas BLG forms a second adsorption layer below the hydrophobin layer (Fig. 8a), as indicated by the experiments with thin foam films in Ref. [28]. In contrast, at $0.94<x_{\mathrm{BLG}}<1$ the concentration of HFBII is too low, so that the hydrophobin cannot cover the interface with a dense solidifying layer. In this case, a mixed adsorption layer of BLG + HFBII is formed (Fig. 8b), which leads to a significant decrease in both $E_{\text {sh }}$ and $\eta_{\text {sh }}$, as seen in Fig. 10b. Our results on foam stability imply 
that the mixed RP + HFBII adsorption layers (unlike those with dense HFBII monolayer) cannot prevent the bubble coalescence and/or the Ostwald ripening that leads to foam destruction within $1-2$ hours.

Our results are in agreement with a recent paper by Tcholakova et al. [48], where it was demonstrated that the addition of amphiphilic molecules (like lauric and myristic acids that engender surface phase transition) essentially suppresses the Ostwald ripening in surfactant stabilized foams. These authors concluded that the main reason for the reduced rate of bubble Ostwald ripening in the systems with high surface modulus is the low solubility and diffusivity of the gas molecules in the respective condensed adsorption layers, which have solid (rather than fluid) molecular packing. The formation of such condensed adsorption layers can be detected by measuring the dilatational [30,31,48] and shear [10,26-29] surface moduli. Both of them have greater values for condensed layers due to lateral cohesion between the adsorbed molecules. In particular, nonzero surface shear elasticity, $E_{\mathrm{sh}}>0$, represents the criterion for surface solidification that is related to strong lateral cohesion between the adsorbed molecules and to the formation of dense adsorption layers.

\section{Conclusions}

Hydrophobins are proteins that (unlike most proteins) possess the property of excellent foam stabilizers [9]. Here, we investigate the effect of $\mathrm{pH}$ and addition of other proteins on the foaminess, bubble size, and stability of foams from aqueous solutions of the protein HFBII hydrophobin. The produced stable foams have bubbles of radii smaller than $40 \mu \mathrm{m}$ that obey the lognormal distribution. The overrun of most foams was in the range from 5 to 8 , which indicates a good foaminess of the investigated solutions.

The foam stability was characterized by the time dependences of foam volume and weight, the latter being an indicator for the water content in the foam. A combined quantitative criterion for foam longevity, the degree of foam conservation, $D_{\mathrm{FC}}$, was proposed; see Eq. (9) and Fig. 5. Small decreases in the foam volume and weight was observed only during the first three days of their storage. During the next 12-17 days, no further changes were observed in the produced very stable foams. This can be explained with the formation of dense hydrophobin adsorption layers, 
which are impermeable to gas transfer from smaller to bigger bubbles in the foam. Thus, the Ostwald ripening (one of the main reasons for foam destabilization) is blocked. Moreover, the population of small bubbles that are formed in the HFBII solutions (i) stops the drainage of water through the Plateau borders (Fig. 6); (ii) increases the air volume fraction, and (iii) improves the foam longevity. The variation of $\mathrm{pH}$ does not essentially affect the foaminess and foam stability, which could be explained with the predominant hydrophobic interactions in the HFBII adsorption layers [46]. The addition of "regular" proteins, such as $\beta$-lactoglobulin, ovalbumin and bovine serum albumin, to the HFBII solutions does not deteriorate the quality and stability of the produced foams up to $94 \%$ weight fraction of the regular protein. At higher fractions of the added regular proteins, the foams become unstable because of the occurrence of bubble coalescence and/or Ostwald ripening. In the latter case, the amount of hydrophobin in the solution is insufficient to form dense adsorption layers (Fig. 8b), which could stop the gas transfer across the foam films and prevent the foam disproportionation. The fact that the shear elasticity and viscosity of the protein adsorption layers correlate with the foam stability (Fig. 10), implies that surface rheological data can be used as indicator for foam stability. The results and conclusions from the present study could be useful in the applications of hydrophobins as foam stabilizers.

\section{Acknowledgments}

The authors gratefully acknowledge the support from Unilever R\&D, from the FP7 project Beyond-Everest, and from EU COST Action CM1101. The authors are thankful to Prof. Krassimir D. Danov for consulting the statistical data processing and for critical reading of the manuscript.

\section{Supplementary information}

Appendices A, B, C and D can be found in the online version at http://dx.doi.org/10.1016/j.colsurfa.2016.06.018...

\section{References}

[1] E. Rio, W. Drenckhan, A. Salonen, D. Langevin, Unusually stable liquid foams, Adv. Colloid Interface Sci. 205 (2014) 74-86.

[2] E. Dickinson, Exploring the frontiers of colloidal behaviour where polymers and particles meet, Food Hydrocolloids 52 (2016) 497-509. 
[3] J. Wang, A.V. Nguyen, S. Farrokhpay, A critical review of the growth, drainage and collapse of foams, Adv. Colloid Interface Sci. 228 (2016) 55-70.

[4] A. Bureiko, A. Trybala, N. Kovalchuk, V. Starov, Current applications of foams formed from mixed surfactant-polymer solutions, Adv. Colloid Interface Science 222 (2015) 670677.

[5] A. Bureiko, A. Trybala, J. Huang, N. Kovalchuk, V. Starov, Effects of additives on the foaming properties of Aculyn 22 and Aculyn 33 polymeric solutions, Colloids Surf. A 460 (2014) 265-271.

[6] A. Bureiko, A. Trybala, J. Huang, N. Kovalchuk, V. Starov, Bulk and surface rheology of AculynTM 22 and AculynTM 33 polymeric solutions and kinetics of foam drainage, Colloids Surf. A 434 (2013) 268- 275.

[7] I. Lesov, S. Tcholakova, N. Denkov, Factors controlling the formation and stability of foams used as precursors of porous materials, J. Colloid Interface Sci. 426 (2014) 9-21.

[8] A.R. Cox, F. Cagnol, A.B. Russell, M.J. Izzard, Surface properties of class II hydrophobins from Trichoderma reesei and influence on bubble stability, Langmuir 23 (2007) 79958002.

[9] A.R. Cox, D.L. Aldred, A.B. Russell, Exceptional stability of food foams using class II hydrophobin HFBII, Food Hydrocolloids 23 (2009) 366-376.

[10] T.B J. Blijdenstein, P.W.N.de Groot, S.D. Stoyanov, On the link between foam coarsening and surface rheology: why hydrophobins are so different, Soft Matter 6 (2010) 1799-1808.

[11] G. Gochev, I. Retzlaff, D. Exerowa, R. Miller, Electrostatic stabilization of foam films from $\beta$-lactoglobulin solutions, Colloids Surf. A 460 (2014) 272-279.

[12] K.G. Marinova, E.S. Basheva, B. Nenova, M. Temelska, A.Y. Mirarefi, B. Campbell, I.B. Ivanov, Physico-chemical factors controlling the foamability and foam stability of milk proteins: sodium caseinate and whey protein concentrates. Food Hydrocolloids 23 (2009) 1864-1876.

[13] K.G. Marinova, R.D. Stanimirova, M.T. Georgiev, N.A. Alexandrov, E.S. Basheva, P.A. Kralchevsky, Co-adsorption of the proteins $\beta$-casein and BSA in relation to the stability of thin liquid films and foams, in P. Kralchevsky, R. Miller, F. Ravera (Eds.), Colloid and Interface Chemistry for Nanotechnology, CRC Press, Boca Raton, FL, 2013, pp. 439-458, http://www.crcnetbase.com/doi/abs/10.1201/b15262-22.

[14] T.B.J. Blijdenstein, R.A. Ganzevles, P.W.N. de Groot, S.D. Stoyanov, On the link between surface rheology and foam disproportionation in mixedhydrophobin HFBII and whey protein systems, Colloids Surf. A 438 (2013) 13-20.

[15] M. Reger, T. Sekine, T. Okamoto, H. Hoffmann, Unique emulsions based on biotechnically produced hydrophobins, Soft Matter 7 (2011) 8248-8257. 
[16] M. Reger, T. Sekine, H. Hoffmann, Boosting the stability of protein emulsions by the synergistic use of proteins and clays, Colloid Polym. Sci. 290 (2012) 631-640.

[17] F.L. Tchuenbou-Magaia, I.T. Norton, P.W. Cox, Hydrophobins stabilised air-filled emulsions for the food industry, Food Hydrocolloids 23 (2009) 1877-1885.

[18] A.J. Green, K.A. Littlejohn, P. Hooley, P.W. Cox, Formation and stability of food foams and aerated emulsions: Hydrophobins as novel functional ingredients, Curr. Opin. Colloid Interface Sci. 18 (2013) 292-301.

[19] M. Qin, L.-K. Wang, X.-Z. Feng, Y.-L. Yang, R. Wang, C. Wang, L. Yu, B. Shao, M.-Q. Qiao, Bioactive surface modification of mica and poly(dimethylsiloxane) with hydrophobins for protein immobilization, Langmuir 23 (2007) 4465-4471.

[20] X. Li, S. Hou, X. Feng, Y. Yu, J. Ma, L. Li, Patterning of neural stem cells on poly(lacticco-glycolic acid) film modified by hydrophobin, Colloids Surf., B 74 (2009) 370-374.

[21] M.B. Linder, Hydrophobins: proteins that self assemble at interfaces, Curr. Opin. Colloid Interface Sci. 14 (2009) 356-363.

[22] M. Lienemann, J.-A. Gandier, J.J. Joensuu, A. Iwanaga, Y. Takatsuji, T. Haruyama, E. Master, M. Tenkanen, M.B. Linder, Structure-function relationships in hydrophobins: Probing the role of charged side chains, Applied Environmental Microbiology 79 (2013) 5533-5538.

[23] H.A.B. Wösten, K. Scholtmeijer, Applications of hydrophobins: current state and perspectives, Appl. Microbiol. Biotechnol. 99 (2015) 1587-1597.

[24] J. Hakanpää, A. Paananen, A. Askolin, T. Nakari-Setälä, T. Parkkinen, M. Penttilä, M.B. Linder, J. Rouvinen, Atomic resolution structure of the HFBII hydrophobin, a selfassembling amphiphile, J. Biological Chem. 279 (2004) 534-539.

[25] S. Askolin, M. Linder, K. Scholtmeijer, M. Tenkanen, M. Penttila, M.L. de Vocht, H.A.B. Wösten, Interaction and comparison of a class I hydrophobin from Schizophyllum commune and class II hydrophobins from Trichoderma reesei, Biomacromolecules 7 (2006) 1295-1301.

[26] G.M. Radulova, K. Golemanov, K.D. Danov, P.A. Kralchevsky, S.D. Stoyanov, L.N. Arnaudov, T.B.J. Blijdenstein, E.G. Pelan, A. Lips. Surface shear rheology of adsorption layers from the protein HFBII hydrophobin: Effect of added $\beta$-casein, Langmuir 28 (2012) 4168-4177.

[27] K.D. Danov, G.M. Radulova, P.A. Kralchevsky, K. Golemanov, S.D. Stoyanov. Surface shear rheology of hydrophobin adsorption layers: Laws of viscoelastic behaviour with applications to long-term foam stability, Faraday Discuss. 158 (2012) 195-221.

[28] K.D. Danov, P.A. Kralchevsky, G.M. Radulova, E.S. Basheva, S.D. Stoyanov, E.G. Pelan. Shear rheology of mixed protein adsorption layers vs their structure studied by surface force measurements. Adv. Colloid Interface Sci. 222 (2015) 148-161. 
[29] G.M. Radulova, K.D. Danov, P.A. Kralchevsky, J.T. Petkov, S.D. Stoyanov. Shear rheology of hydrophobin adsorption layers at oil/water interfaces and data interpretation in terms of a viscoelastic thixotropic model, Soft Matter 10 (2014) 5777-5786.

[30] K.D. Danov, R.D. Stanimirova, P.A. Kralchevsky, K.G. Marinova, S.D. Stoyanov, T.B.J. Blijdenstein, A.R. Cox, E.G. Pelan. Adhesion of bubbles and drops to solid surfaces, and anisotropic surface tensions studied by capillary meniscus dynamometry, Adv. Colloid Interface Sci. (2016) DOI: 10.1016/j.cis.2015.06.003

[31] N.A. Alexandrov, K.G. Marinova, T.D. Gurkov, K.D. Danov, P.A. Kralchevsky, S.D. Stoyanov, T.B.J. Blijdenstein, L.N. Arnaudov, E.G. Pelan, A. Lips, Interfacial layers from the protein HFBII hydrophobin: dynamic surface tension, dilatational elasticity and relaxation times, J. Colloid Interface Sci. 376 (2012) 296-306.

[32] E. Aumaitre, S. Wongsuwarn, D. Rossetti, N.D. Hedges, A.R. Cox, D. Vella, P. Cicuta, A viscoelastic regime in dilute hydrophobin monolayers, Soft Matter 8 (2012) 1175-1183.

[33] R.D. Stanimirova, T.G. Gurkov, P.A. Kralchevsky, K.T. Balashev, S.D. Stoyanov, E.G. Pelan, Surface pressure and elasticity of hydrophobin HFBII layers on the air-water interface: rheology vs structure detected by AFM imaging, Langmuir 29 (2013) 60536067.

[34] J. Burke, A. Cox, J. Petkov, B.S Murray. Interfacial rheology and stability of air bubbles stabilized by mixtures of hydrophobin and $\beta$-casein, Food Hydrocolloids 34 (2014) 119127.

[35] R.D. Stanimirova, K.G. Marinova, K.D. Danov, P.A. Kralchevsky, E.S. Basheva, S.D. Stoyanov, E.G. Pelan, Competitive adsorption of the protein hydrophobin and an ionic surfactant: Parallel vs sequential adsorption and dilatational rheology, Colloids Surf. A 457 (2014) 307-317.

[36] K.D. Danov, R.D. Stanimirova, P.A. Kralchevsky, K.G. Marinova, N.A. Alexandrov, S.D. Stoyanov, T.B.J. Blijdenstein, E.G. Pelan. Capillary meniscus dynamometry - method for determining the surface tension of drops and bubbles with isotropic and anisotropic surface stress distributions, J. Colloid Interface Sci. 440 (2015) 168-178.

[37] Cs. Kotsmar, D. Arabadzhieva, Khr. Khristov, E. Mileva, D.O. Grigoriev, R. Miller, D. Exerowa, Adsorption layer and foam film properties of mixed solutions containing $\beta$-casein and $\mathrm{C}_{12}$ DMPO, Food Hydrocolloids 23 (2009) 1169-1176.

[38] X.L. Zhang, J. Penfold, R.K. Thomas, I.M. Tucker, J.T. Petkov, J. Bent, A. Cox, I. Grillo, Self-assembly of hydrophobin and hydrophobin/surfactant mixtures in aqueous solution, Langmuir 27 (2011) 10514-10522.

[39] X.L. Zhang, J. Penfold, R.K. Thomas, I.M. Tucker, J.T. Petkov, J. Bent, A. Cox, Adsorption behavior of hydrophobin and hydrophobin/surfactant mixtures at the solidsolution interface, Langmuir 27 (2011) 10464-10474. 
[40] M. Torkkeli, R. Serimaa, O. Ikkala, M. Linder, Aggregation and self-assembly of hydrophobins from Trichoderma reesei: low-resolution structural models, Biophys. J. 83 (2002) 2240-2247.

[41] G.R. Szilvay, T. Nakari-Setälä, M.B. Linder, Behavior of Trichoderma reesei hydrophobins in solution: interactions, dynamics, and multimer formation, Biochemistry 45 (2006) 85908598.

[42] K. Kisko, G.R. Szilvay, U. Vainio, M.B. Linder, R. Serimaa, Interactions of hydrophobin proteins in solution studied by small-angle X-ray scattering, Biophys. J. 94 (2008) 198206.

[43] K. Kisko, G.R. Szilvay, E. Vuorimaa, H. Lemmetyinen, M.B. Linder, M. Torkkeli, R. Serimaa, Self-assembled films of hydrophobin proteins HFBI and HFBII studied in situ at the air/water interface, Langmuir 25 (2009) 1612-1619.

[44] M. Krasowska, C.A. Prestidge, D.A. Beattie, Atomic force microscopy for determining surface interactions of relevance for food foams and emulsions, in Y.L. Dar, J.M. Light (Eds.), Food Texture Design and Optimization, Wiley, New York, 2014, pp. 402-422. DOI: 10.1002/9781118765616.ch16

[45] E.S. Basheva, P.A. Kralchevsky, N.C. Christov, K.D. Danov, S.D. Stoyanov, T.B.J. Blijdenstein, H.-J. Kim, E.G. Pelan, A. Lips, Unique properties of bubbles and foam films stabilized by HFBII hydrophobin, Langmuir 27 (2011) 2382-2392.

[46] E.S. Basheva, P.A. Kralchevsky, K.D. Danov, S.D. Stoyanov, T.B.J. Blijdenstein, E.G. Pelan, A. Lips, Self-assembled bilayers from the protein HFBII hydrophobin: nature of the adhesion energy, Langmuir 27 (2011) 4481-4488.

[47] I.M. Tucker, J.T. Petkov, J. Penfold, R.K. Thomas, A.R. Cox, N. Hedges, Adsorption of hydrophobin-protein mixtures at the air-water interface: The impact of $\mathrm{pH}$ and electrolyte, Langmuir 31 (2015) 10008-10016.

[48] S. Tcholakova, Z. Mitrinova, K. Golemanov, N.D. Denkov, M. Vethamuthu, K.P. Ananthapadmanabhan, Control of Ostwald ripening by using surfactants with high surface modulus, Langmuir 27 (2011) 14807-14819.

[49] P. Stevenson, Inter-bubble gas diffusion in liquid foam, Curr. Opin. Colloid Interface Sci. 15 (2010) 374-381.

[50] A. Raymundo, J. Empis, I. Sousa, Method to evaluate foaming performance, J. Food Eng. 36 (1998) 445-452.

[51] R.M. Wiley, Limited coalescence of oil droplets in coarse oil-in-water emulsions, J. Colloid Sci. 9 (1954) 427-437.

[52] S. Tcholakova, N.D. Denkov, I.B. Ivanov, B. Campbell, Coalescence in $\beta$-lactoglobulinstabilized emulsions: Effects of protein adsorption and drop size, Langmuir 18 (2002) 8960-8971. 
[53] S. Tcholakova, N.D. Denkov, D. Sidzhakova, I.B. Ivanov, B. Campbell, Interrelation between drop size and protein adsorption at various emulsification conditions, Langmuir 19 (2003) 5640-5649.

[54] S. Arditty, C.P. Whitby, B.P.; Binks, V. Schmitt, F. Leal-Calderon, Some general features of limited coalescence in solid-stabilized emulsions, Eur. Phys. J. E 11 (2003) 273-281.

[55] H. Jin, W. Zhou, J. Cao, S.D. Stoyanov, T.B.J. Blijdenstein, P.W.N. de Groot, L.N. Arnaudov, E.G. Pelan, Super stable foams stabilized by colloidal ethyl cellulose particles, Soft Matter 8 (2012) 2194-2205.

[56] G.E.P. Box, J.S. Hunter, W.G. Hunter, Statistics for Experiments: Design, Innovation, and Discovery; $2^{\text {nd }}$ ed. Wiley, Hoboken, NJ, 2005.

[57] E.L. Crow, K. Shimizu (Eds.) Lognormal Distributions: Theory and Applications, Marcel Dekker, New York, 1988.

[58] G.A. Korn, T.M. Korn, Mathematical Handbook, McGraw-Hill, New York, 1968.

[59] H.M. Princen, Pressure/volume/surface area relationships in foams and highly concentrated emulsions: role of volume fraction, Langmuir 4 (1988) 164-169.

[60] R.S. Farr, R.D. Groot, Close packing density of polydisperse hard spheres, J. Chem. Phys. 131 (2009) 244104.

[61] T.H. Whitesides, D.S. Ross, Experimental and theoretical analysis of the limited coalescence process: Stepwise limited coalescence, J. Colloid Interface Sci. 169 (1995) 4859.

[62] K. Golemanov, S. Tcholakova, P.A. Kralchevsky, K.P. Ananthapadmanabhan, A. Lips, Latex-particle-stabilized emulsions of anti-Bancroft type, Langmuir 22 (2006) 4968-4977.

[63] H. Fisher, I. Polikarpov, A.F. Craievich, Average protein density is a molecular-weightdependent function, Protein Sci. 13 (2004) 2825-2828.

[64] N.D. Denkov, Mechanisms of action of mixed solid-liquid antifoams. 2. Stability of oil bridges in foam films, Langmuir 15 (1999) 8530-8542.

[65] P.A. Kralchevsky, K. Nagayama, Particles at Fluid Interfaces and Membranes, Elsevier, Amsterdam, 2001, Chapter 14, pp. 591-632.

[66] A. Lohrasbi-Nejad, M. Torkzadeh-Mahani, S. Hosseinkhani, Heterologous expression of a hydrophobin HFB1 and evaluation of its contribution to producing stable foam, Protein Expr. Purif. 118 (2016) 25-30.

[67] A. Saint-Jalmes, M.-L. Peugeot, H. Ferraz, D. Langevin, Differences between protein and surfactant foams: microscopic properties, stability and coarsening. Colloids Surf. A, 263 (2005) 219-225.

[68] P. Wierenga, H. Gruppen, New views on foams from protein solutions. Curr. Opin. Colloid Interface Sci. 15 (2010) 365-373. 
[69] P.R. Garrett, J.D. Hines, S.C. Joyce, P.T. Whittal, Report prepared for Unilever R\&D, Port Sunlight, UK, 1993.

[70] S. Mukherjee, H. Wiedersich, Morphological and viscoelastic properties of dense foams generated from skin cleansing bars. Colloids Surf. 95 (1995) 159-172.

[71] R. Lemlich, Prediction of changes in bubble size distribution due to interbubble gas diffusion in foam. Ind. Eng. Chem. Fundamen. 17 (1978) 89-93.

[72] H.C. Cheng, R. Lemlich, Errors in the measurement of bubble size distribution in foam. Ind. Eng. Chem. Fundamen. 22 (1983) 105-109.

[73] J.J. Adams, B.F. Anderson, G.E. Norris, L.K. Creamer, G.V.B. Jameson, Structure of bovine $\beta$-lactoglobulin (variant A) at very low ionic strength, J. Struct. Biol. 154 (2006) 246-254.

[74] J. Krägel, S.R. Derkatch, R. Miller, Interfacial shear rheology of protein-surfactant layers. Adv. Colloid Interface Sci. 144 (2008) 38-53.

[75] S. Jordens, P.A. Rühs, C. Sieber, L. Isa, P. Fischer, R. Mezzenga, Bridging the gap between the nanostructural organization and macroscopic interfacial rheology of amyloid fibrils at liquid interfaces, Langmuir 30 (2014) 10090-10097. 


\title{
Supplementary Information
}

for the article

\section{Production and characterization of stable foams with fine bubbles from} solutions of hydrophobin HFBII and its mixtures with other proteins ${ }^{\text {* }}$

\author{
Lydia M. Dimitrova ${ }^{a}$, Plamen V. Petkov ${ }^{\text {a }}$, Peter A. Kralchevsky ${ }^{\text {a }}$, \\ Simeon D. Stoyanov ${ }^{\text {b,c,d }}$, Eddie G. Pelan ${ }^{\mathrm{b}}$ \\ a Department of Chemical and Pharmaceutical Engineering, Faculty of Chemistry and Pharmacy, \\ Sofia University, 1164 Sofia, Bulgaria \\ ${ }^{\mathrm{b}}$ Unilever Research \& Development Vlaardingen, 3133AT Vlaardingen, The Netherlands \\ ${ }^{\mathrm{c}}$ Laboratory of Physical Chemistry and Colloid Science, Wageningen University, 6703 HB Wageningen, \\ The Netherlands \\ ${ }^{\mathrm{d}}$ Department of Mechanical Engineering, University College London, WC1E 7JE, UK
}

Here, the reference numbers are the same as in the main text of the article.

\section{Appendix A. Relation between foam overrun and mean bubble radius}

Here, our goal is to derive Eq. (4) in the main text of the article. At the first step, we will follow the approach, developed by Tcholakova et al. [52,53] for emulsions. The volume of the gas in the bubbles, $V_{\mathrm{g}}$, and the total area of the air/water interface in the foam, $S_{\mathrm{aw}}$, can be expressed as follows:

$$
V_{\mathrm{g}}=\sum_{i} \frac{4}{3} \pi R_{i}^{3}, \quad S_{\mathrm{aw}}=\sum_{i} 4 \pi R_{i}^{2}
$$

where the summation is carried out over all bubbles in the foam. It has been assumed that the bubbles are spherical; $R_{i}$ is the radius of the $i$-th bubble. In view of the definition of $R_{32}$, Eq. (3) in the main text, the ratio of $V_{\mathrm{g}}$ and $S_{\mathrm{aw}}$ can be presented in the form:

$$
\frac{V_{\mathrm{g}}}{S_{\mathrm{aw}}}=\frac{\sum_{i} R_{i}^{3}}{3 \sum_{i} R_{i}^{2}}=\frac{R_{32}}{3}
$$


Furthermore, the protein adsorption, $\Gamma$, i.e. the mass of adsorbed protein per unit area of the air/water interface, can be expressed in the form [52,53]:

$$
\Gamma=\frac{c_{\mathrm{p}} V_{\mathrm{w}}}{S_{\mathrm{aw}}}=\frac{c_{\mathrm{p}} V_{\mathrm{w}} R_{32}}{3 V_{\mathrm{g}}}=\frac{c_{\mathrm{p}} R_{32}(1-\Phi)}{3 \Phi}
$$

Here, the total area of the air/water interface, $S_{\mathrm{aw}}$, has been substituted from Eq. (A.2); $c_{\mathrm{p}}$ is the mass of protein (per unit volume of the water phase), which has been adsorbed on the bubble surfaces; $V_{\mathrm{w}}=(1-\Phi) V_{\mathrm{F}}$ is the volume of the water phase; as before, $V_{\mathrm{F}}$ is the foam volume; $\Phi$ is the volume fraction of gas in the foam, and the volume of gas in the foam can be expressed in the form $V_{\mathrm{g}}=\Phi V_{\mathrm{F}}$. To obtain Eq. (A.3), it has been assumed that in the initial moment the whole amount of the aqueous solution has been transformed into foam.

At the second step, we assume that the protein in the aqueous phase is present in the form of aggregates, the smallest "aggregates” being separate protein molecules. Then, the protein adsorption, $\Gamma$, and the area fraction occupied by the protein at the air/water interface, $\varphi_{\mathrm{a}}$, can be expressed in the form:

$$
\Gamma=\frac{\sum_{j} \frac{4}{3} \pi a_{j}^{3} \rho_{\mathrm{p}}}{S_{\mathrm{aw}}}, \quad \varphi_{\mathrm{a}}=\frac{\sum_{j} \pi a_{j}^{2}}{S_{\mathrm{aw}}}
$$

Here, it has been assumed that the aggregates are (approximately) spherical; $a_{j}$ is the radius of the $j$-th aggregate; the summation is carried out over all aggregates; $\rho_{\mathrm{p}}$ is the mass density of the protein. Taking the ratio of the two expressions in Eq. (A.4), we obtain:

$$
\frac{\Gamma}{\varphi_{\mathrm{a}}}=\frac{4}{3} \rho_{\mathrm{p}} \frac{\sum_{j} a_{j}^{3}}{\sum_{j} a_{j}^{2}}=\frac{4}{3} \rho_{\mathrm{p}} a_{32}
$$

where the definition of $a_{32}$ has been used. Further, $c_{\mathrm{p}}$ can be presented in the form:

$$
c_{\mathrm{p}}=\frac{M_{\mathrm{p}}}{V_{\mathrm{w}}}=\frac{M_{\mathrm{p}}}{M_{\mathrm{w}} / \rho_{\mathrm{w}}} \approx \frac{M_{\mathrm{p}} \rho_{\mathrm{w}}}{M_{\mathrm{w}}+M_{\mathrm{p}}}=w_{\mathrm{p}} \rho_{\mathrm{w}}
$$

Here, $\rho_{\mathrm{w}}$ is the mass density of water; $M_{\mathrm{p}}$ and $M_{\mathrm{w}}$ are, respectively, the masses of the adsorbed protein and of the water phase; we have used the approximation $M_{\mathrm{p}}<<M_{\mathrm{w}} ; w_{\mathrm{p}}$ is the mass fraction of the adsorbed protein. In the case of good foaming, most of the protein is in the form of 
adsorption layers on the bubble surfaces, the amount of protein in the serum being negligible. In such a case, $w_{p}$ can be identified with the input mass fraction of protein in the water phase. Finally, in Eq. (A.3) we substitute $\Gamma$ and $c_{\mathrm{p}}$ from Eqs. (A.5) and (A.6); thus, we obtain:

$$
4 \varphi_{\mathrm{a}} \rho_{\mathrm{p}} a_{32}=w_{\mathrm{p}} \rho_{\mathrm{w}} R_{32} \frac{1-\Phi}{\Phi}
$$

By definition, the foam overrun is $O_{\mathrm{vr}}=\Phi /(1-\Phi)$ and consequently Eq. (A.7) is equivalent to Eq. (4) in the main text.

\section{Appendix B. Description of the changes observed in the stable foams upon storage}

Different types of changes have been observed in the investigated stable foams after three days of storage. They are described in Table B.1.

Table B.1. Types of changes observed in the stable foams after their storage for three days

\begin{tabular}{|c|c|c|}
\hline Type & Stability & Description of the foam after storage \\
\hline A & Excellent & $\begin{array}{l}\text { No cavities appear in the foam and there is no liquid drainage out } \\
\text { of the foam, completely stable foam. }\end{array}$ \\
\hline B & $\begin{array}{l}\text { Very stable: small } \\
\text { cavities appear; no } \\
\text { water drainage }\end{array}$ & $\begin{array}{l}\text { Cavities appear; some of them are large, but there is no drainage } \\
\text { of liquid out of the foam. }\end{array}$ \\
\hline $\mathrm{C}$ & $\begin{array}{l}\text { Stable without } \\
\text { cavities, but with } \\
\text { water drainage }\end{array}$ & $\begin{array}{l}\text { No visible cavities are observed in the foam, but some amount of } \\
\text { liquid has drained below the foam. }\end{array}$ \\
\hline $\mathrm{D}$ & $\begin{array}{l}\text { Small cavities with } \\
\text { drainage }\end{array}$ & $\begin{array}{l}\text { Small cavities have appeared in the foam and some amount of } \\
\text { liquid has drained below the foam. }\end{array}$ \\
\hline $\mathrm{E}$ & $\begin{array}{l}\text { Larger cavities with } \\
\text { drainage }\end{array}$ & $\begin{array}{l}\text { The cavities have significant size; some amount of liquid was } \\
\text { drained below the foam, but the total foam volume still remains } \\
\text { unchanged. }\end{array}$ \\
\hline
\end{tabular}

Because the changes stop after the third day and the foam remains unchanged upon longer storage, the appearance of cavities (voids) and the drainage of a small amount of liquid can be attributed to a slow process of limited bubble coalescence, analogous to the limited coalescence in Pickering emulsions. 
Table B.2. Types of changes observed in stable foams from HFBII solutions at three different $\mathrm{pH}$ values; see Table B.1 for the symbol definitions

\begin{tabular}{|c|c|c|c|}
\hline HFBII concentration & $\mathrm{pH}=4.3$ & $\mathrm{pH}=6.0$ & $\mathrm{pH}=10.1$ \\
\hline $0.2 \mathrm{wt} \%$ & $\mathrm{D}$ & $\mathrm{A}$ & $\mathrm{C}$ \\
\hline $0.3 \mathrm{wt} \%$ & $\mathrm{E}$ & $\mathrm{A}$ & $\mathrm{C}$ \\
\hline $0.4 \mathrm{wt} \%$ & $\mathrm{E}$ & $\mathrm{C}$ & $\mathrm{C}$ \\
\hline $0.5 \mathrm{wt} \%$ & $\mathrm{E}$ & $\mathrm{D}$ & $\mathrm{C}$ \\
\hline $0.7 \mathrm{wt} \%$ & $\mathrm{C}$ & $\mathrm{D}$ & $\mathrm{C}$ \\
\hline $0.9 \mathrm{wt} \%$ & $\mathrm{D}$ & - & $\mathrm{B}$ \\
\hline $1.0 \mathrm{wt} \%$ & - & $\mathrm{A}$ & $\mathrm{B}$ \\
\hline
\end{tabular}

The data in Table B.2 presents data for the type of changes observed in hydrophobinstabilized foams after three days of storage. The data indicate that the smallest changes are observed with the foams at $\mathrm{pH}=6$, i.e. near the isoelectric point of HFBII. A possible explanation can be that in this case more and bigger hydrophobin aggregates are formed. They are sandwiched in the foam films and prevent the further film drainage. In this way, the limited bubble coalescence is blocked.

Table B.3. Types of changes observed in stable foams from mixed solutions of HFBII (varying concentration) with $0.5 \mathrm{wt} \%$ BLG, OVA and BSA; see Table B.1 for the symbol definitions

\begin{tabular}{|c|c|c|c|}
\hline HFBII concentration & BLG (18.3 KDa) & OVA (45 KDa) & BSA (66.4 KDa) \\
\hline $0.05 \mathrm{wt} \%$ & B & - & D \\
\hline $0.1 \mathrm{wt} \%$ & E & D & E \\
\hline $0.2 \mathrm{wt} \%$ & C & C & D \\
\hline $0.3 \mathrm{wt} \%$ & A & B & C \\
\hline $0.4 w t \%$ & B & B & D \\
\hline $0.5 w t \%$ & A & C & \\
\hline
\end{tabular}


The stable foams from mixed solutions of HFBII + regular protein, BLG, OVA and BSA (Table B.3) behave similarly to foam stabilized by HFBII alone (see above). For this reason, the changes observed in these foams upon storage can be also explained with a slow process of limited bubble coalescence. The changes are the smallest for the films from the mixed solutions of HFBII with the smallest regular protein, BLG, and the greatest for the bigger regular protein, BSA; the protein molecular weights are also given in Table B.3. This coincidence could be fortuitous because not only single protein molecules, but also protein aggregates play important role for the stabilization of the foam films.

\section{Appendix C. Coarsening in the foams produced from solutions of regular proteins}

The increase of bubble size with time in the foams from solutions of regular proteins, BLG, BSA and OVA, was monitored by means of the prism method by Garrett et al. [69,70]. A sample of the foam was placed in a Petri dish (of depth $1 \mathrm{~mm}$ ), and covered with an optical prism. The cross-section of the latter is an isosceles rectangular triangle. Pictures have been taken every $50 \mathrm{~s}$ and automatically recorded by DIGIMICRO 2.0 Scale camera of $1600 \times 1280$ optical resolution. The record continued about $3 \mathrm{~h}$ for all investigated solutions. Later, the obtained pictures were manually scaled by ImageJ software.

Images obtained by the method of Garrett et al. are shown in Fig. C.1. In these pictures, the areas of the wetting films pressed against the prism surface are seen. In Fig. C.2, we have plotted the experimental data for the mean surface-to-number radius of the wetting films, $r_{21}(t)$ as a function of time. As established by Lemlich et al. [71,72], under such a configuration, $r_{21}$ is the statistically adequate physical characteristic of the bubble size.

Fig. C.2 shows results for $r_{21}(t)$ for foams produced from solutions of $0.5 \mathrm{wt} \%$ BSA, BLG and OVA. The bubble growth is the slowest for the foam from the BSA solution, $\approx 158 \mu \mathrm{m} / \mathrm{h}$, and the fastest for the foam from the OVA solution, $\approx 321 \mu \mathrm{m} / \mathrm{h}$. In all cases, the foams produced from solutions of regular proteins completely decayed within 2.5 - 3.5 hours. 


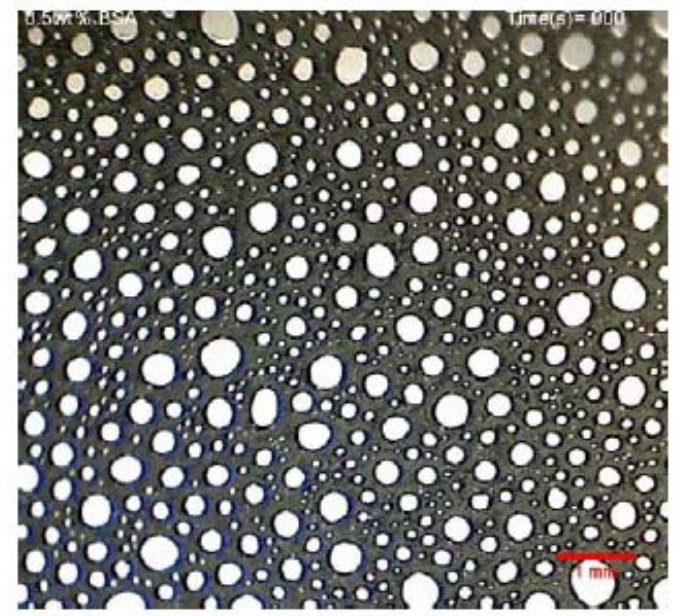

(a) $0.5 \mathrm{wt} \% \mathrm{BSA}$ at $0 \mathrm{~s}$;

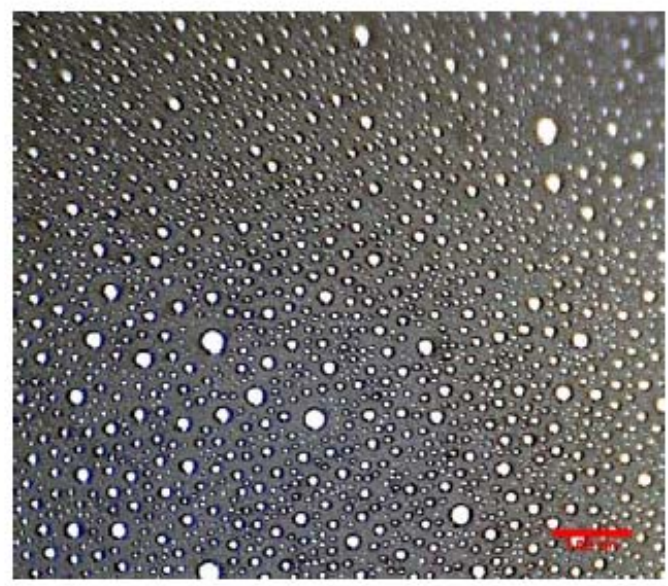

(c) $0.5 \mathrm{wt} \% \mathrm{BLG}$ at $0 \mathrm{~s}$

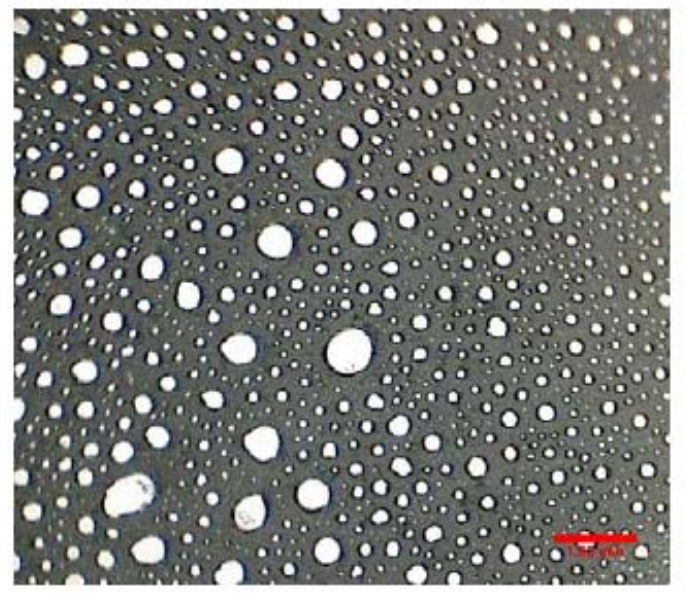

(e) $0.5 \mathrm{wt} \% \mathrm{OVA}$ at $0 \mathrm{~s}$

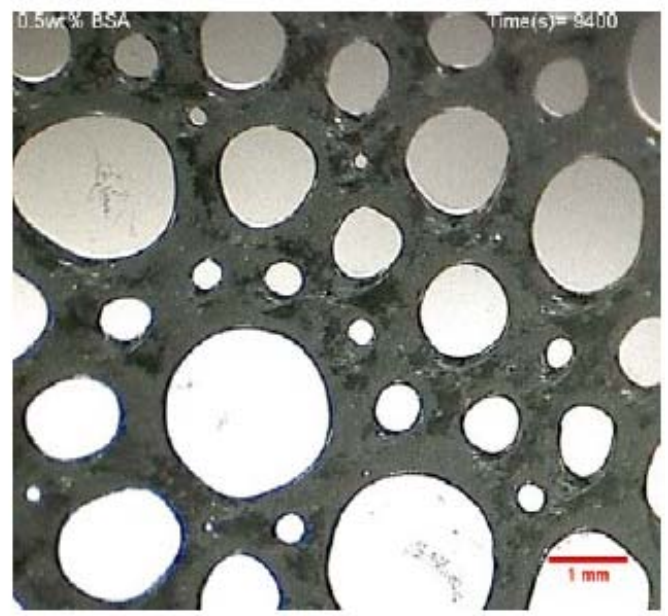

(b) $0.5 \mathrm{wt} \% \mathrm{BSA}$ after $2.6 \mathrm{~h}$

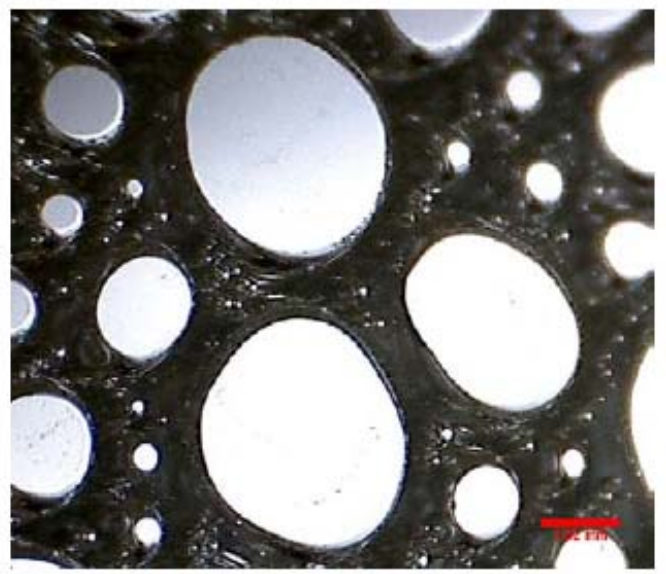

(d) $0.5 \mathrm{wt} \%$ BLG after $3.3 \mathrm{~h}$

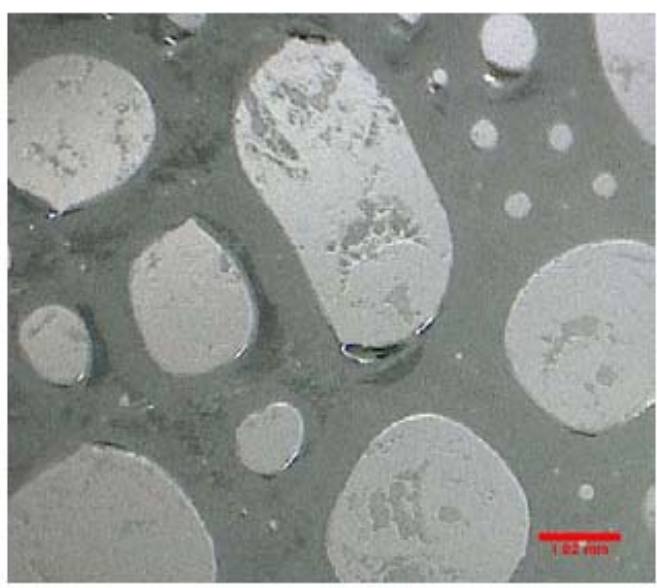

(f) $0.5 \mathrm{wt} \% \mathrm{OVA}$ at $2.8 \mathrm{~h}$

Fig. C.1. Photographs of foams from protein solutions studied by the prism method by Garrett et al. [69,70]; the scaling bar corresponds to $1.0 \mathrm{~mm}$. 


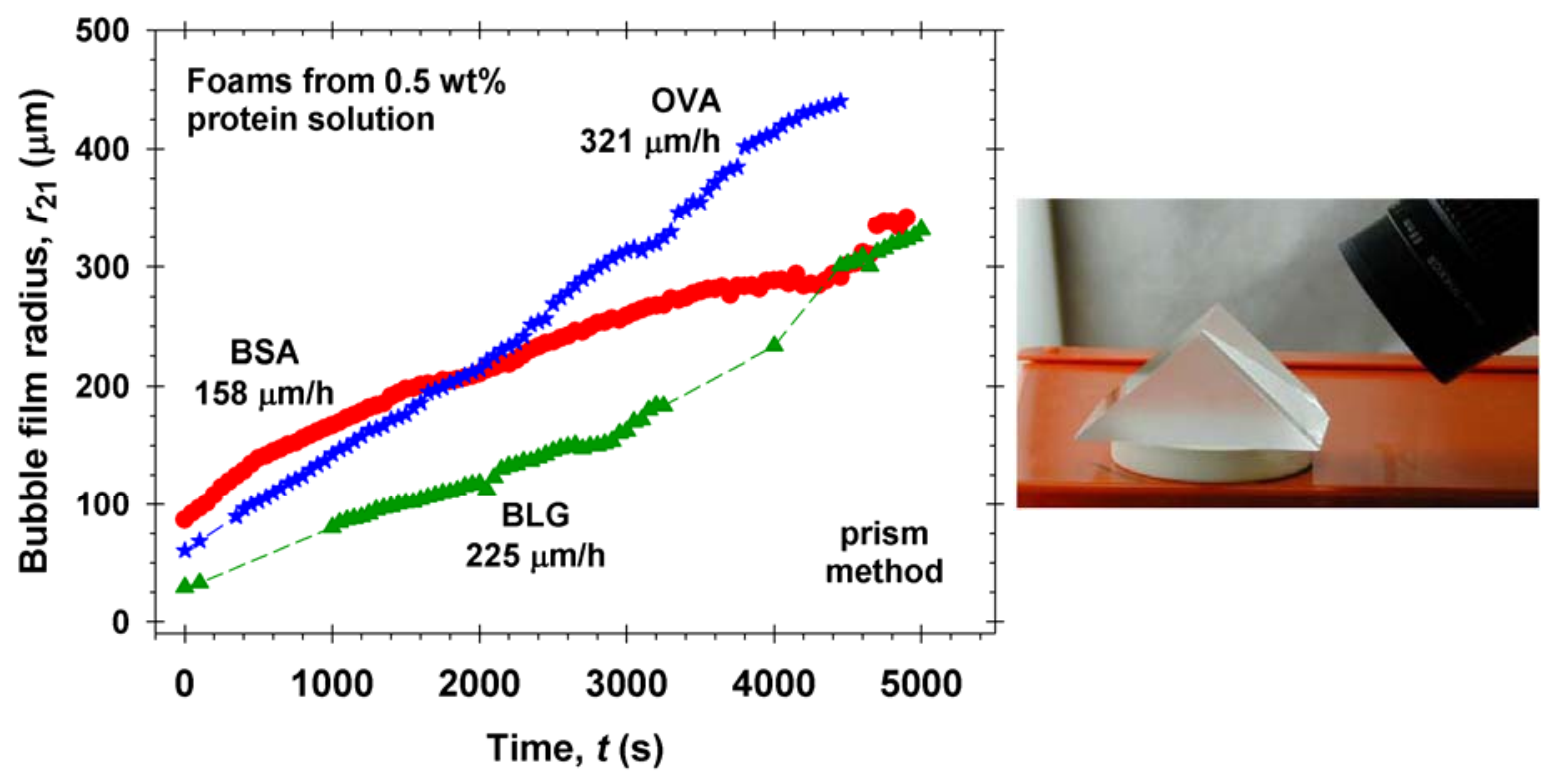

Fig. C.2. Plot of the mean bubble-film radius, $r_{21}$, vs. time $t$ : experimental data obtained using the prism method by Garrett et al. [69,70]; see the photograph to the right and Fig. C.1. The experimental curves correspond to foams obtained from $0.5 \mathrm{wt} \%$ solutions of OVA, BSA and BLG (no HFBII). The average rates of increase of $r_{21}$ are shown in the figure.

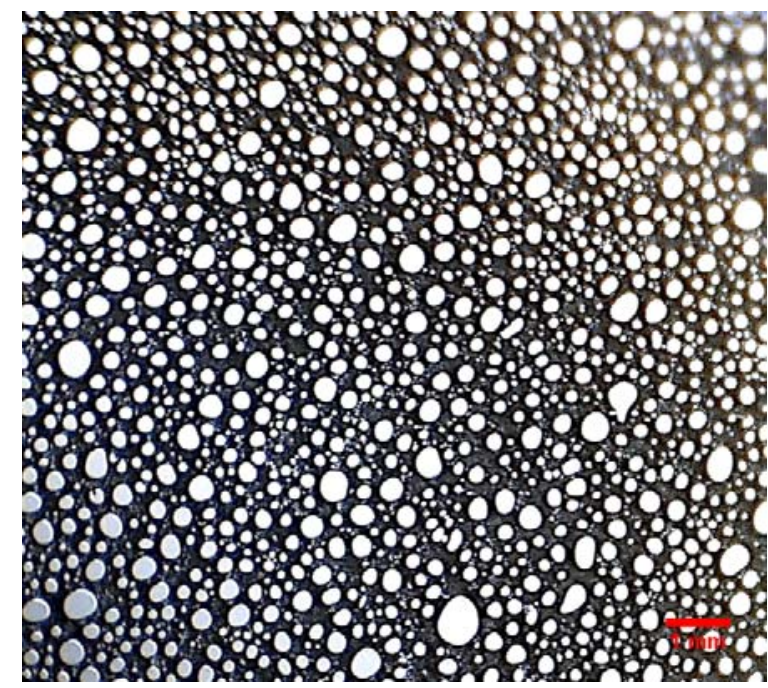

(a) just after ceasing the stirring

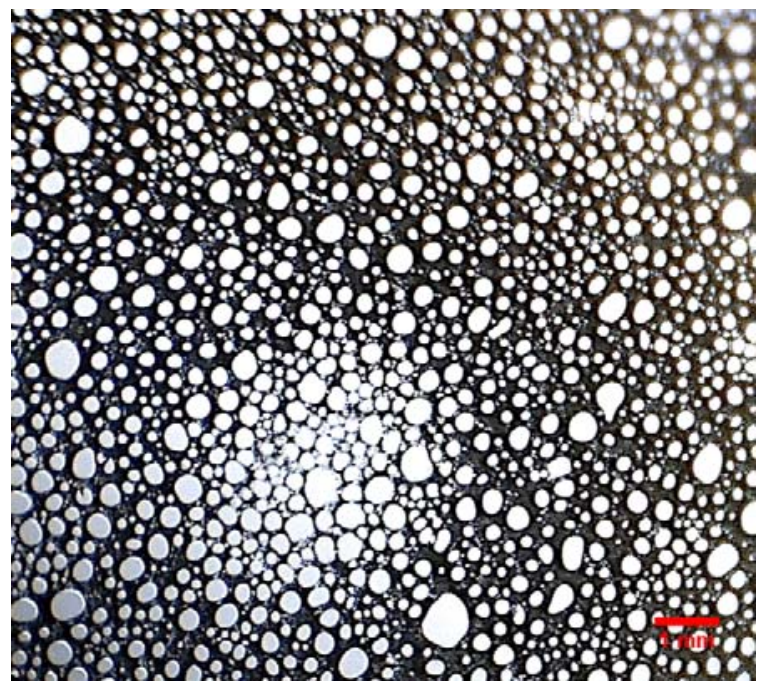

(b) 3 hours later

Fig. C.3. Photographs of foams from $0.1 \mathrm{wt} \%$ HFBII solution $(\mathrm{pH}=6.0)$ taken by using the prism method by Garrett et al. [69,70]: (a) just after ceasing the stirring and (b) $3 \mathrm{~h}$ later. The foam was obtained with sequential use of the mixer 1 for $60 \mathrm{~s}$ and mixer 2 for $120 \mathrm{~s}$. 
Fig. C.3 shows analogous pictures taken for foams produced from $0.1 \mathrm{wt} \%$ HFBII solution. In this experiment, the protein concentration was 5 times lower than that in Fig. C.1. The reason was to produce bigger bubbles, because the optical system of the prism method has a low magnification and application of this method to foams with smaller size (like those studied in the main part of this article) is impossible. A comparison between the photographs in Figs. C.1 and C.3 show that the foam produced from the HFBII solution (even at a lower concentration) is stable within 3 hours, unlike the foams from the solutions of regular proteins. Some small differences between the two photos in Fig. C.3 are due to an accidental local deformation (depression) of the foam rather than to foam coarsening.

\section{Appendix D. Gas volume fractions in the investigated foams}

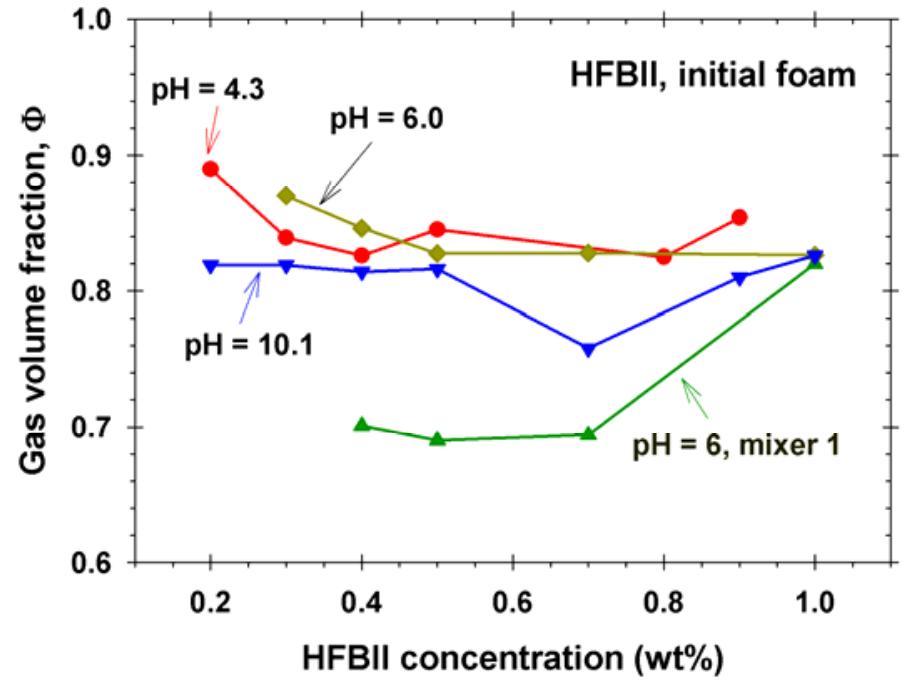

(a)

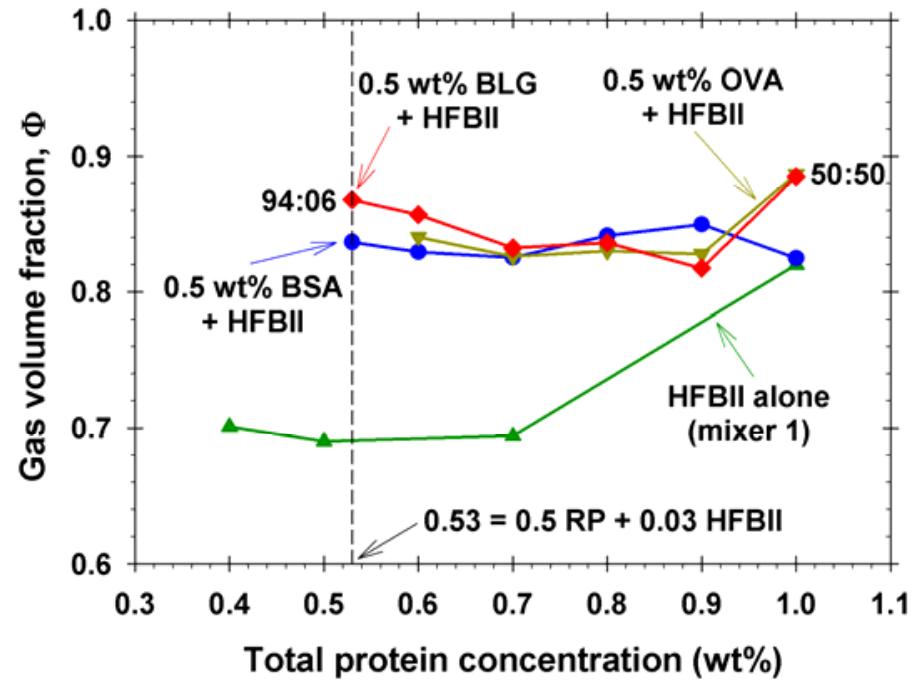

(b)

Fig. D.1. Plots of the gas volume fraction $\Phi$ in the studied foams vs. the protein concentration. (a) Data for $\Phi$ corresponding to the overrun from Fig. 3a. (b) Data for $\Phi$ corresponding to the overrun from Fig. 7a.

The gas volume fraction $\Phi$ in the studied foams is in the range between 0.70 and 0.90 . These relatively high values of $\Phi$ can be due to bubble deformations [59]; polydispersity [60], and elongated shape. Note that HFBII is able to stabilize not only $\mu$ m-sized, but also submicron bubbles [45], which are not visible in our photographs, but influence the measured weight of the foam. 